\begin{tabular}{|c|c|c|c|c|c|}
\hline MUNIBE Antropologia-Arkeologia & $\mathrm{n}^{\circ} 68$ & $251-272$ & DONOSTIA & 2017 & ISSN 1132-2217 • elSSN 2172-4555 \\
\hline
\end{tabular}

\title{
De "iglesia" tardoantigua a mezquita califal. Revisión arqueológica de las estructuras conservadas en calle Rey Heredia 20 (Córdoba)
}

\author{
From late antique "church" to caliphal mosque: archaeological \\ review of the remains conserved in Rey Heredia 20 street (Córdoba)
}

PALABRAS CLAVES: Domus, edificio cultual, Antigüedad Tardía, Califato omeya, Península Ibérica, Mezquita.

GAKO-HITZAK: Domus, eraikin kulturala, Antzinaro Berantiarra, Kalifaldi omeiatarra, Iberiar penintsula.

KEY WORDS: Domus, religious building, Late Antiquity, Umayyad Caliphate, Iberian Peninsula, Mosque.

Manuel D. RUIZ-BUENO(1) y Carmen GONZÁLEZ-GUTIÉRREZ ${ }^{(1)}$

\section{RESUMEN}

En las inmediaciones de la actual Mezquita-Catedral de Córdoba se conserva un imponente edificio cuya secuencia estratigráfica es muy compleja y su andadura histórica muy dilatada. Esta construcción, que a partir del siglo XIII funcionó como iglesia del antiguo convento de Santa Clara, ha sido objeto de numerosos estudios arqueológicos y arquitectónicos que no siempre han estado interconectados, generando numerosas dudas aún por esclarecer. Esta realidad, junto con la necesidad imperante de la revisión de las estructuras, tanto emergentes como exhumadas en el subsuelo, de la citada construcción, nos ha motivado a estudiar y a contextualizar de forma crítica su secuencia estratigráfica bajo imperial, tardoantigua y andalusí (siglos III-XIII). Gracias a dicho análisis hemos podido matizar antiguas interpretaciones y plantear otras nuevas que pueden contribuir a mejorar nuestro conocimiento tanto de una polémica construcción preislámica vinculada a las clases dirigentes (domus o iglesia), como de la posterior mezquita califal.

\section{LABURPENA}

Gaur egun Kordobako Meskita-Katedrala dagoen tokiaren inguruan, sekuentzia estratigrafiko oso konplexua eta ibilbide historiko oso luzea dituen eraikin bikain bat ikus daiteke. XIII. mendetik aurrera Santa Clara konbentu zaharreko eliza gisa erabili izan zuten eraikin hura eta bertan arkeologiako eta arkitekturako ikerketa ugari egin izan duten arren, azterlan horiek ez dira beti elkarri lotuta egon eta oraindik ere argitzeke dauden zalantza ugari sortu dute. Hori guztia dela eta, aipatutako eraikinaren egiturak (gorantz doazenak zein lur azpian aterata daudenak) berrikusteko dagoen behar handia dela eta, bertako sekuentzia estratigrafikoa modu kritikoan aztertu eta testuinguruan jasotzea erabaki dugu: inperio-garaia, antzinaro berantiarra eta andalustarra. Azterketa horri esker, garai bateko interpretazio batzuk argitu eta klase gidariei (domus edo eliza) lotutako Islamaren aurreko eraikuntza polemikoaren zein ondorengo kalifa-meskitaren inguruko gure ezagutza hobetzen lagun dezaketen interpretazio berri batzuk planteatu ahal izan ditugu.

\section{ABSTRACT}

Near the current Mosque-Cathedral of Córdoba, that is to say, in the heart of the historical center of the city, there is conserved an imposing building with a very complex stratigraphic sequence and a very substantial historical background. This construction, which served as a church in the former convent of Santa Clara from the 13th century, has been the subject of numerous archaeological and architectural studies that have not always been interconnected. This has generated doubts regarding the interpretation of the uses and functions of the aforementioned building in some of its phases, which in many cases still require further clarification. This reality, together with the prevailing and needed review of the structures, both emergent and exhumed in the subsoil, of the building, has motivated us to study and contextualize critically its stratigraphic sequence in the late imperial, late antique and andalusi centuries (in other words, from the 3rd to the 13th centuries). Thanks to this analysis, we have been able to reposition several traditional interpretations and to propose new ones, hoping that our work contributes to improve our knowledge about the controversial pre-Islamic construction linked to the ruling classes (domus or church) as well as about the later Caliphal mosque.

\footnotetext{
(1) Grupo de Investigación Sísifo (PAIDI HUM-236). Departamento de Historia del Arte, Arqueología y Música de la Universidad de Córdoba. Facultad de Filosofía y Letras. Plaza del Cardenal Salazar, 3, 14003, Córdoba. Correos-e: mdruizbueno@gmail.com y carmengonz28@gmail. com. ORCID ID: http://orcid.org/0000-0001-9265-6979 y http://orcid.org/0000-0003-0893-3932 respectivamente.
} 


\section{1.- INTRODUCCIÓN}

En el número 20 de la cordobesa calle Rey Heredia $^{1}$, se conserva la antigua iglesia de Santa Catalina, perteneciente al ya desaparecido convento de Santa Clara. Fue un establecimiento conventual ${ }^{2}$ fundado tras la conquista castellana de la ciudad, que reutilizó varias estructuras precedentes entre las que destaca una mezquita andalusí. Esta última ha sido objeto de diversas menciones y estudios en la historiografía ( vid. infra), aun cuando las primeras actuaciones arqueológicas que afectaron a su subsuelo no se acometieron hasta 1981 (Olmo, 1981). Los datos obtenidos en esta primera intervención fueron desigualmente complementados y ampliados en lo sucesivo, pudiéndose destacar la intervención desarrollada entre los meses de febrero y abril de 1995 (Marfil, 1996a), o el estudio arqueológico y arquitectónico llevado a cabo en 2006 (Caballero et al., 2007).

Aun cuando los resultados de las citadas intervenciones han redundado en un mejor conocimiento de la fase pre-conventual del conjunto, ha prevalecido la desconexión entre ellas, así como la difícil accesibilidad a sus resultados. Como consecuencia, la polémica acerca de la exacta funcionalidad, fisonomía y cronología de las estructuras tardoantiguas descubiertas, o las dudas sobre la cronología inicial y tipología de la posterior mezquita, siguen vigentes. Dichos factores vienen motivando, desde hace años, la necesidad de una revisión y puesta al día de la documentación generada por las distintas intervenciones y que aquí hemos reseñado someramente ${ }^{3}$. A lo largo de las siguientes páginas, y en la medida de lo posible, trataremos de analizar, contextualizar ${ }^{4}$ e interpretar de forma crítica la evolución de esta parcela urbana a la luz tanto de la sistematización de la documentación, inédita o publicada, a la que hemos tenido acceso, como de la observación de las estructuras visibles ${ }^{5}$.

\section{LOCALIZACIÓN, INSERCIÓN URBANÍSTICA Y EVOLUCIÓN DE LAS ESTRUCTURAS DOCU- MENTADAS}

La fundación de la colonia de Corduba hacia los años 169-168 o 152-151 a.C., supuso la creación de un asentamiento de gran extensión (unas 47 hectáreas) en el espolón de una terraza cuaternaria, situada a más de 400 m del río Guadalquivir. En época tardorrepublicana, o ya augustea, se derribó el lienzo meridional de la primitiva muralla, ensanchándose la urbe republicana hasta el Baetis (Vaquerizo y Ruiz, 2014: 16-18). El resultado fue una ciudad con una superficie intramuros de aproximadamente 78 hectáreas, de las que 31 corresponden a esta última ampliación o "nova urbs", donde se ubica el solar objeto de nuestro estudio.

Este nuevo sector quedó articulado mediante una serie de calles entre las que destacan los dos ramales del kardo maximus: el occidental, que desembocaba en la denominada como Puerta del Puente; y el oriental, que adoptó una orientación noroeste-sureste y llegaba a la antigua Puerta Piscatoria (Ruiz Bueno, 2015: 82-87). Este último ramal, cuyo recorrido parece haberse mantenido inalterado a lo largo de los dos últimos milenios, coincide con la actual calle Rey Heredia, que perpetúa su trazado. El impacto que esta arteria ha tenido siempre en los distintos edificios erigidos en el número 20 de la citada calle ha quedado de manifiesto en la orientación de los mismos: sureste-noroeste y noreste-suroeste. En este rasgo también pudo influir la existencia de otro posible eje viario romano, hoy fosilizado parcialmente en la calle Osio, que corría perpendicular al citado ramal y que constituye el límite noroccidental del solar objeto de estudio (fig. 1).

\footnotetext{
1 La calle Rey Heredia también ha recibido la denominación de calle de Francos (entre mediados del siglo XIII y el siglo XV) o Portería de Santa Clara (Escribano, 1964-65: 84; Marfil et al., 1996a).

2 Sobre dicho establecimiento contamos con algunos estudios de carácter artístico y arquitectónico que han abordado aspectos como los soportes, arcos, fachadas y portadas, la cubierta o la heráldica del inmueble conventual (Jordano, 2002: 27-61; 2013: 70-71). Tampoco podemos olvidar una reciente síntesis histórica sobre el complejo conventual femenino desde su fundación en 1261 (Dobado e Yllescas, 2014 : 48-49).

${ }^{3}$ Por tratarse de una cuestión derivada, en la presente contribución dejamos al margen el estudio de orientación o modulación del edificio islámico, tratado en González Gutiérrez, 2017.

${ }^{4}$ La contextualización de la documentación arqueológica de calle Rey Heredia 20 con la procedente de otros solares del entorno es una tarea compleja debido a la escasez de intervenciones arqueológicas en las inmediaciones. Entre las excepciones destacan las excavaciones llevadas a cabo en puntos como el antiguo teatro romano (Ventura et al., 2002) o la sala de abluciones oriental de la mezquita aljama (Montejo, 1998), por citar solo las más significativas.

${ }^{5}$ No hemos podido consultar el informe de la intervención realizada por L. Olmo en 1981, por lo que los datos que manejamos al respecto han sido extraídos de los trabajos de P. Marfil (1996a, 1996b, 1996c) y L. Caballero et al. (2007). Del mismo modo, la memoria correspondiente a la Intervención Arqueológica de Urgencia (en adelante, I.A.U.) realizada en 1995 por P. F. Marfil permanece inédita, y tan sólo hemos podido acceder a la información relativa a los sondeos 2, 4, y 5. Para paliar esta situación tuvimos oportunidad de realizar, gracias a las gestiones del Dr. J. F. Murillo, dos visitas técnicas al edificio, en noviembre de 2014 y junio de 2017. Sin embargo, el mal estado general del inmueble, la escasa accesibilidad a algunas de sus partes, el soterramiento de gran parte de las estructuras exhumadas en las intervenciones arqueológicas precedentes y la falta de iluminación general, dificultaron la labor de documentación, medición y, sobre todo, de registro fotográfico.
} 


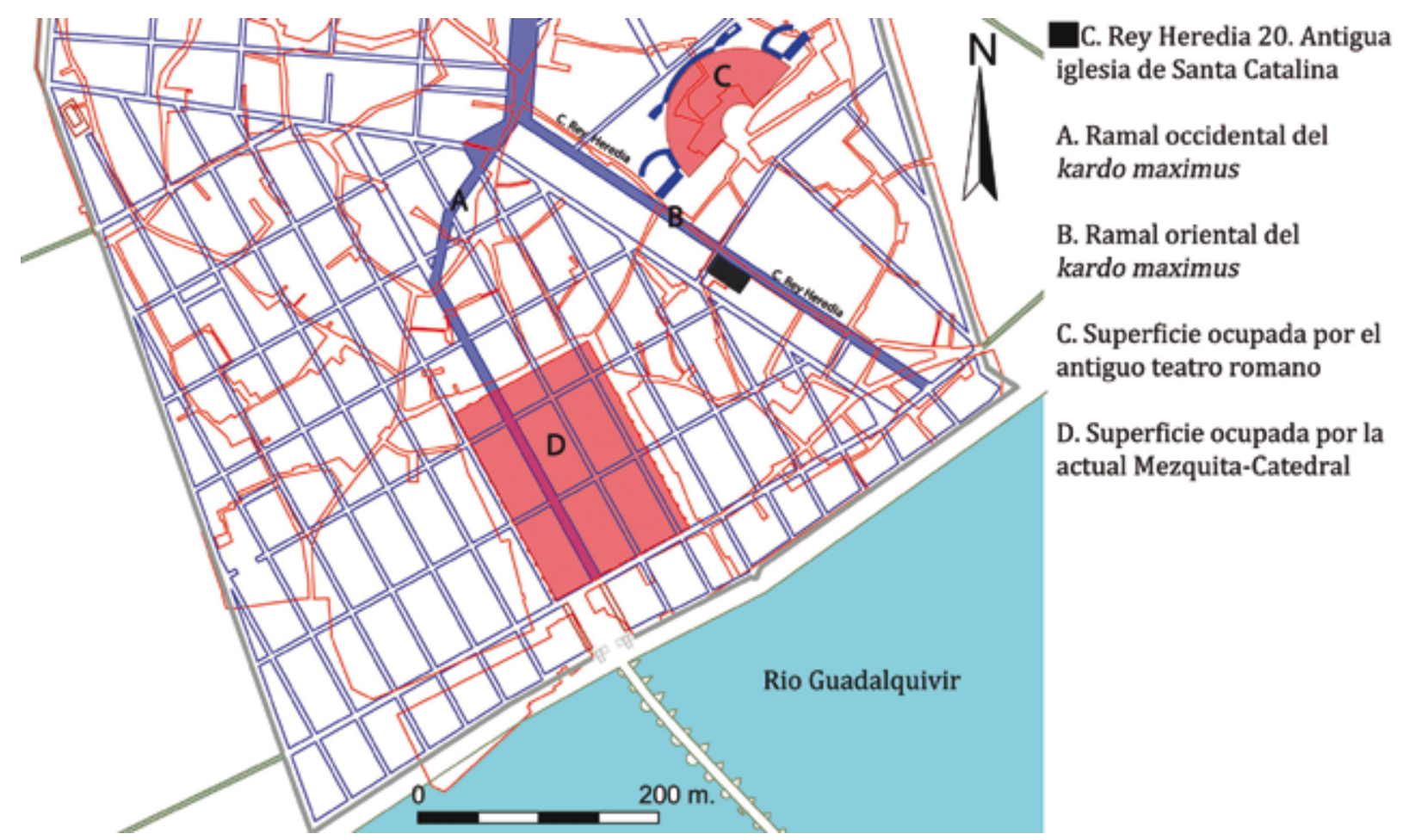

Fig. 1. Córdoba (mitad meridional de la antigua medina): callejero hipotético hacia el año 100 (superpuesto al actual) y con indicación de los principales puntos mencionados en el texto. Modificado a partir de Ruiz Bueno, 2016: fig. 314. / Córdoba (southern half of the ancient medina quarter): hypothetical street plan around $100 \mathrm{AD}$ (overlapped to the current street map). Main locations named in the text have been highlighted. Modified from Ruiz Bueno, 2016 : fig. 314.

\subsection{Fase bajoimperial (SS. III-V)}

Las evidencias más antiguas de ocupación documentadas hasta la fecha en este solar, y teniendo en cuenta que no se ha agotado su secuencia estratigráfica, consisten en varios elementos aislados e inconexos. Si excluimos un conducto de saneamiento datado de forma genérica en época altoimperial, localizado en el corte $5^{6}$ y que quizás evacuó en la posible vía fosilizada en la actual calle Osio, el testimonio más antiguo y mejor datado es un pozo negro del siglo III (corte 2). Se trata de una oquedad colmatada con abundantes restos óseos y de fauna doméstica, que para P. Marfil (1996a) refleja "el uso marginal de esta zona de la ciudad en esta época". Es cierto que las limitadas dimensiones de la superficie intervenida impiden matizar tal aseveración, pero la inutilización del cercano teatro (fig. 1) y del sistema de plazas que lo rodeaban, hacia los años 50-60 del siglo III (Monterroso, 2002: 138-143; Ventura y Pizarro, 2010: 198-199), parece haber dado pistoletazo de salida a una dinámica en la que tanto el edificio lúdico como sus inmediaciones (incluyendo el solar objeto de nuestro estudio) pudieron haberse transformado durante varias décadas en un área con menor atractivo e interés. Esta circunstancia explicaría algunos fenómenos docu- mentados en el entorno, como la inutilización de parte de la red viaria y de saneamiento (con cloacas colmatadas y superficies de tránsito ocultas bajo niveles de vertidos); el abandono de todo tipo de edificaciones; la aparición de centros artesanales de diversa índole (destinados a la extracción de materiales constructivos, o bien, a la elaboración de cal, teselas e instrumentos óseos), o la proliferación de vertederos (Ruiz Bueno, 2016: 515, 546 y 654). Nos encontraríamos, en definitiva, ante una ocupación menos densa y cohesionada que, quizás, y a modo de cautelosa hipótesis, podría explicar la escasa entidad de las evidencias halladas en calle Rey Heredia 20 para este momento (Ruiz Bueno, 2016: 719 y 720).

En este solar también salió a la luz una estructura interpretada como una tumba de los siglos IV-V. Se trataba de una cista de piedras irregulares de pequeño y mediano tamaño, con un enlucido interno de cal recubierto con estuco de color ocre-amarillo, y que debió de contener restos óseos humanos si nos atenemos tanto a la información oral proporcionada por P. Marfil, como a los datos recogidos en la memoria científica resultante de la I.A.U. En ella se alude al hallazgo de huesos en el relleno de la zanja de cimentación de un muro del siglo VI que seccionó la cista (U.E. 220, corte 2).

\footnotetext{
${ }^{6}$ Salvo que se indique lo contrario, dicho término alude a los distintos sondeos realizados en 1995 por P. Marfil en el interior de la antigua iglesia de Santa Catalina. Tras la intervención arqueológica, la mayor parte de las estructuras halladas volvieron a quedar ocultas bajo tierra, por lo que tan solo hemos podido observar in situ, y de forma segura, las halladas en los cortes 4 y 9.
} 
La aparición de sepulturas en la superficie in urbe de Corduba ha sido un fenómeno tradicionalmente adscrito a momentos tardíos (siglos VI-VII), limitado a la superficie ocupada por la vetus urbs republicana, y que parecía evidenciar el despoblamiento de dicho sector (Carrillo et al., 1999: 59). Esta visión peyorativa no solo ha sido matizada en fechas recientes ${ }^{7}$, sino que en los últimos años han salido a la luz tumbas de los siglos IV-V en otros puntos del extremo meridional de la urbe, lo que contradice la interpretación clásica que limitaba esta práctica funeraria a la mitad septentrional de la Córdoba romana (Ruiz Bueno, 2016: 335 y 338-339).

Del mismo modo, los enterramientos intramuros en el Occidente Romano tienden a vincularse actualmente a dos tipos de construcciones: inmuebles sacros cristianos (rodeados, por lo general, de auténticas áreas cementeriales); o establecimientos residenciales y/o productivos, (como parece ocurrir en el caso que nos ocupa), en cuyas inmediaciones fueron practicadas determinadas tumbas (Azkarate, 2002: 125-129; Ruiz Bueno, 2017).

\subsection{Fase tardoantigua (SS. VI-VII)}

En esta etapa fueron levantadas varias estructuras que describimos someramente a continuación siguiendo los cortes en los que fueron halladas (fig. 2). Se trata de restos de escasa o nula accesibilidad, por lo que las descripciones que aquí recogemos se basan en gran medida en las informaciones recogidas en Marfil, 1996a; 1996b; 1996c; 2000 y Penco, 2000; 2002 y en la inspección visual de los restos hoy en día visibles.

- Corte 2: pavimento de opus vermiculatum realizado con teselas calizas y marmóreas de color blanco. Estaba delimitado al norte por un muro con orientación noroeste-sureste y cimentación a base de nódulos de piedra arenisca de tamaño variable (la zanja de cimentación seccionó la tumba referida en el apdo. 2.1). En el extremo septentrional del paramento fue individualizada una pieza de piedra de mina que pudo haber sido la quicialera de una puerta.

- Corte 4: pavimento de mosaico polícromo, elaborado con teselas calizas, de pasta vítrea y de Terra Sigillata Africana. Con unas dimensiones de 4,70 $\mathrm{m}$ de ancho por 5,25 de largo (fig. 3A), estaba delimitado al oeste por un muro orientado en sentido suroeste-noreste (con zócalo a base de bloques de caliza de 0,80 por $0,45 \mathrm{~m}$ calzados mediante ladrillos y alzado de tapial), y al este por un paramento con similar orientación y técnica edilicia. En el centro de este último muro, una jamba lateral delata la existencia de un acceso que daba paso a una estancia decorada con un mosaico de fisonomía desconocida. En cuanto al pavimento polícromo, éste

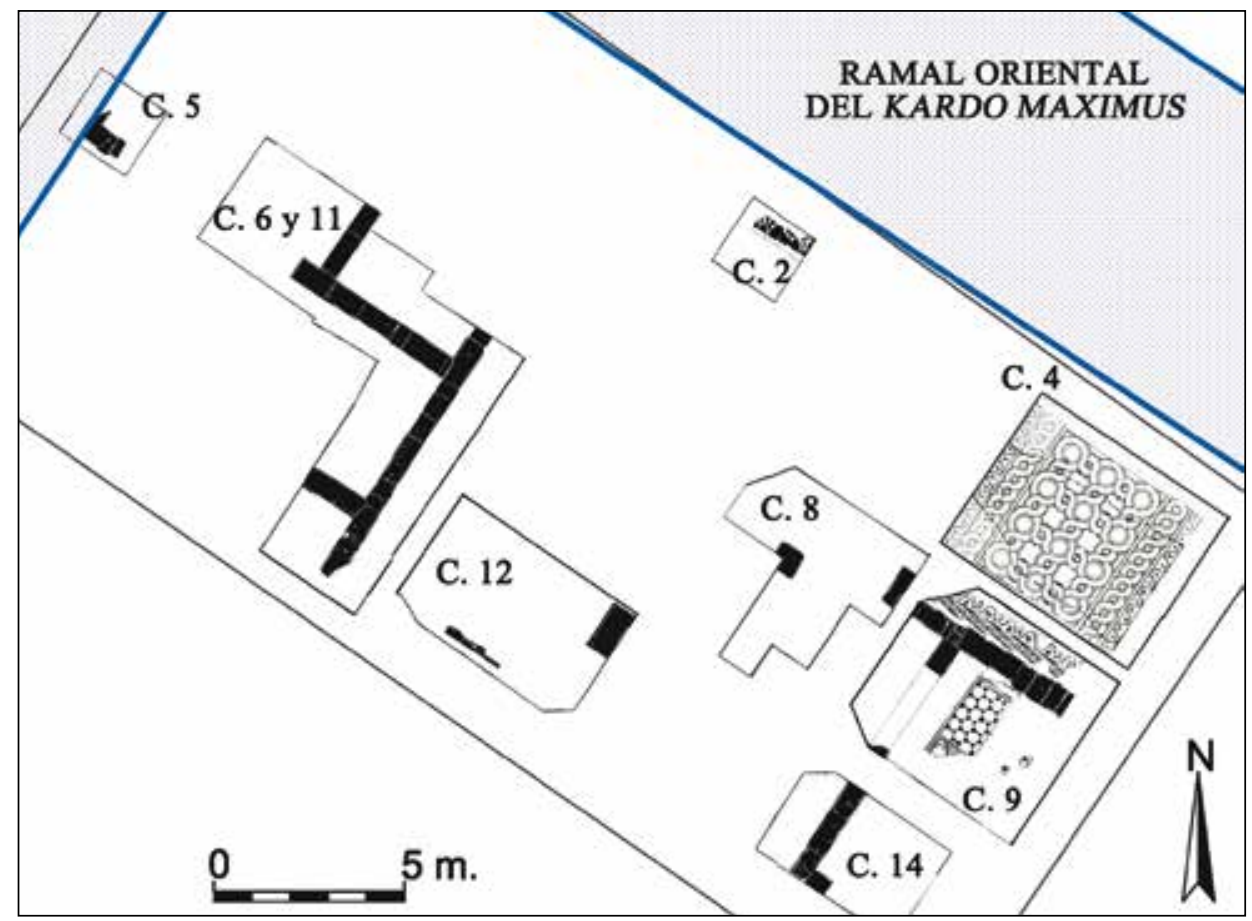

Fig. 2. Córdoba (antigua iglesia de Santa Catalina): estructuras tardoantiguas descubiertas en los distintos cortes practicados durante la I.A.U. realizada en 1995. Modificado a partir de Caballero et al., 2007: fig. 5. I Córdoba (former church of Santa Catalina): late antique archaeological remains discovered in the several areas excavated in 1995. Modified from Caballero et al., 2007: fig. 5 .

\footnotetext{
7 "En el actual estado de la investigación, no podemos interpretar este fenómeno como un decaimiento de los esquemas urbanos, sino como una forma de continuidad. La población aceptaría convivir con sus difuntos intra y extramuros, lo que demuestra que esta práctica sería intrínseca a la forma de entender la ciudad tardoantigua, que comportará un tejido urbano discontinuo, escalonado de sepulturas, espacios con funciones productivas y de habitación" (Sánchez Ramos, 2007: 201).
} 
fue estudiado de manera monográfica por $\mathrm{P}$. Penco (2000; 2002), a cuyos trabajos remitimos. Destaca el campo principal del mosaico, donde es posible apreciar una composición en cuadriculado de círculos grandes y pequeños tangentes por los que discurren peces, alternándose con elementos arquitectónicos (torres). En el interior de los círculos pequeños aparecen flores en cruz y florecillas de cuatro pétalos sobre fondo blan$\mathrm{co}$, mientras que en los mayores tenemos recipientes (cráteras y cestas) y aves (palomas, faisanes y pájaros acuáticos). La combinación de círculos mayores y menores forma octógonos irregulares cóncavos, decorados con parejas de delfines. Por último, dentro del campo central y en el límite de la alfombra, ha podido constatarse la presencia de flores de granada y otros frutos (Penco, 2000: 11; 2002: 248).
- Corte 9: extremo meridional del pavimento musivo polícromo descubierto en el corte 4 . El mosaico estaba delimitado al sur por un muro de sillería y probable alzado de tapial, con una orientación noroeste-sureste, en el que fue posible detectar el umbral de una puerta. En este corte también se identificó otro muro de sillería, con orientación noreste-suroeste, y un mosaico con decoración geométrica y vegetal (fig. 3B).

La documentación disponible acerca del resto de los cortes practicados (fig. 2), es más parca, por lo que tan solo realizaremos algunas breves anotaciones ${ }^{8}$.

La entidad de los restos exhumados ha suscitado diversas hipótesis acerca de la cronología inicial, funcionalidad y configuración espacial de los mismos. Las interpretaciones más relevantes, a las que sumamos la nuestra, son las resumidas a continuación:
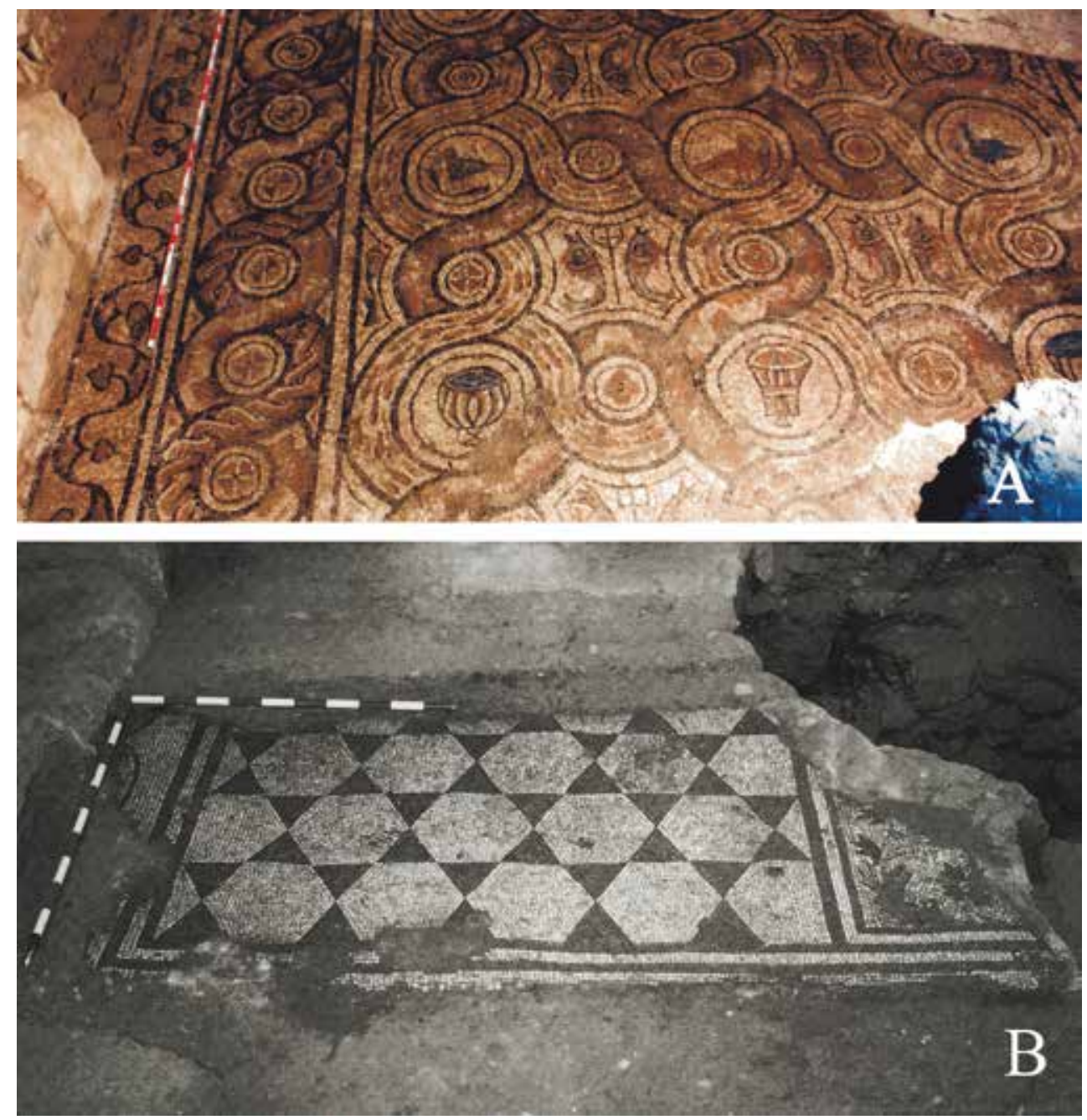

Fig. 3. Córdoba (antigua iglesia de Santa Catalina): A. Mosaico del corte 4 (Penco, 2000: fig. 1). B. Mosaico del corte 9 (Marfil, 2000: foto 9). / A. Córdoba (former church of Santa Catalina): A. Mosaic from area 4 (Penco, 2000: fig. 1). B. Mosaic from area 9 (Marfil, 2000: photo 9).

${ }^{8}$ Corte 5: muro de sillería en sentido noroeste-sureste y cimentado con areniscas que se unía, en ángulo recto, a otro paramento con similar técnica constructiva; cortes 6 y 11: cuatro muros de sillería, dos de ellos en sentido noroeste-sureste y otros dos en sentido noreste-suroeste; corte 8: un pilar cuadrangular y un pavimento de opus vermiculatum de color blanco; corte 12: un pilar rectangular y un muro de sillería con orientación noroeste-sureste, y corte 14: dos muros de sillería, uno con una orientación noroeste-sureste y otro, dispuesto en sentido noreste-suroeste, que se prolongaba hasta el corte 9. 


\section{a) Iglesia de planta de cruz inscrita y cabecera tripartita}

Se trata de la hipótesis tradicional, sostenida por investigadores como P. Marfil (1996a, 1996b, 1996c y 2000) o F. Penco (2000 y 2002). Aboga por la existencia de una ecclesia que pudo estar dedicada al culto martirial. Según dicho planteamiento, habría existido un edificio de planta casi cuadrangular (19,50 m de ancho por 21 de largo) con una posible cabecera tripartita absidada orientada hacia el sureste y que presentaba una cruz griega inscrita (fig. 4A). En cuanto a su organización interna, se individualizaron varios espacios: en primer lugar, la zona central, consistente en la citada cruz griega (a excepción del extremo oriental de su nave central, interpretado como el hipotético sanctuarium). Esta zona se habría pavimentado con un suelo de opus vermiculatum que debió de contar con cuatro pilares. A continuación, el espacio interpretado como sanctuarium, ornamentado con un mosaico con decoración tripartita que acogería la mesa del altar, y delimitado al oeste por un muro que pudo haber sido la base de un cancel. Por último, cuatro cámaras laterales, resultado de la inserción de la cruz griega en un inmueble mayor, de planta rectangular (Marfil, 1996b: 35-37; 1996c: 201-203).

La funcionalidad sacra de este recinto estaría avalada por la planta de cruz inscrita (restituida); su orientación hacia el sureste; la existencia de una tumba martirial previa (cuya memoria perviviría a lo largo de los siglos ${ }^{9}$ ); la presencia de varios elementos litúrgicos ${ }^{10}$, y los motivos representados en el mosaico polícromo. Con respecto a esto último, no solo "la rica y extensa simbología del pavimento y su ubicación en el interior del edificio es muestra evidente que nos encontramos ante una estructura cuyos símbolos de carácter cristiano parecen ser indudables" (Penco 2002: 248), sino que el esquema compositivo y la simbología presentan importantes concomitancias con otros mosaicos identificados en edificios religiosos del Levante mediterráneo, Italia, el norte de África o las Baleares (Penco, 2000: 249-250; 2002: 13-15).

Según esta hipótesis, los paralelos tipológicos de la planta propuesta y del mosaico del corte 4, la propia evolución de la secuencia estratigráfica y los materiales cerámicos hallados, apuntarían hacia una iglesia de la segunda mitad del siglo VI (Penco, 2000: 251; 2002: 15) o del tercer cuarto de dicha centuria (Marfil, 1996b: 41; 1996c: 208).

\section{b) Expediente doméstico}

En los últimos años, varios investigadores (CabaIlero et al., 2007: 13-14; Utrero, 2008: 204-205; 2009: 143-144; Vizcaíno, 2009: 156-157 y 451) han puesto en duda la funcionalidad y cronología expuestas en el apartado previo, y han defendido la existencia de varias estructuras "pertenecientes a momentos diferentes de reforma de un conjunto doméstico" (Caballero et al., 2007: 13), o bien a "un conjunto doméstico del siglo VI, cuyas anomalías sólo pueden explicarse considerando la posible reutilización continua de varias estructuras pertenecientes a distintos momentos históricos constructivos" (Utrero, 2009: 144).

La citada hipótesis, contraria a la existencia de una iglesia, está fundamentada en las variaciones en la orientación de los muros y en la organización general de los espacios propuesta tradicionalmente. También alude a la escasa información disponible sobre la planta de la posible iglesia, cuya superficie desconocemos en más de un 50\% (Utrero, 2008: 204; 2009: 143-144; Vizcaíno, 2009: 451); a los motivos del mosaico polícromo, cuya aparente simbología cristiana "hay que demostrar", y a su ubicación, pues está "desorientado en relación con la orientación de la supuesta iglesia, y en contradicción con ella ya que se dirige al Suroeste, dirección real que no es propia de la cabecera de una iglesia y distinta a la orientación del propuesto ábside que lo haría al Sureste" (Caballero et al., 2007: 13-14). A todo esto hay que sumar la inexistencia de elementos litúrgicos in loco e in situ (Caballero et al., 2007: 13; Utrero, 2008: 205; Vizcaíno, 2009: 157 y 451). De hecho, según L. Caballero et al. (2007: 13), el supuesto apoyo para un cancel hallado en el corte 9 es, en realidad, "un umbral de puerta con las huellas para encajar las hojas de madera que probablemente abre a un patio".

La propuesta de cerramiento del crucero también ha sido puesta en tela de juicio. Para M ${ }^{\mathrm{a}}$. A. Utrero (2009: 143) "los pilares identificados en el espacio central no pudieron ser los soportes de unas arquerías triples" ya que no estaban alineados. Por último, L. Caballero et al. (2007: 14) alude a la ausencia de cultura material, que hace que el edificio pueda corresponder "a mediados del s. VI pero también a una cronología uno o dos siglos anterior".

\section{c) Inmueble religioso o doméstico}

En fechas recientes, I. Sánchez Ramos (2010: 5152) ha analizado algunos de los argumentos esgrimi-

\footnotetext{
9 Realidad que se deduce a partir de la documentación, para época emiral, de una fosa irregular para la "extracción de reliquias" (Marfil, 1996a).

${ }^{10}$ Del antiguo convento de Santa Clara procede un fragmento de placa decorativa donada al Museo Arqueológico en el siglo XIX, y datada entre los siglos VII y VIII (Sánchez Ramos, 2006, vol. II: 225), o entre mediados del VI - inicios del VII (Sánchez Velasco, 2006: 66). Del mismo modo, J. Sánchez Velasco (2006: 206) ha sugerido que otras piezas localizadas "muy cerca de esta iglesia", pudieron ornamentarla, tales como un fragmento de columna de calle Encarnación 3 (s. VII; Sánchez Velasco, 2006: 83), un posible cancel o placa de la plaza Jerónimo Páez (s. VI; Sánchez Velasco, 2006: 54) y un fragmento de placa de la plaza de la Concha (segunda mitad del s. VII; Sánchez Velasco, 2006: 59, o bien, ss. VII-VIII/IX; Sánchez Ramos, 2006, vol. II: 227).
} 
dos para defender bien la existencia de una iglesia de planta de cruz inscrita, bien la de un inmueble doméstico. Para ella, hay ciertos elementos (la tumba anterior al edificio, la iconografía del mosaico polícromo, una posible arquería divisoria y el uso sacro del solar a lo largo de los siglos) que impiden descartar por completo la presencia de una construcción de carácter litúrgico. Por ello, considera necesario incorporar al debate "otro tipo de edificios de carácter religioso, probablemente definidos por una caracterización formal diferente" (Sánchez Ramos, 2010: 52). Así, cita la escasez de iglesias tardoantiguas con planta de cruz inscrita (más frecuentes en la arquitectura altomedieval peninsular); la parquedad de datos que permitan restituir la planta propuesta por P. Marfil (fig. 4B); la reducida muestra de iglesias hispanas tardoantiguas dotadas de un sanctuarium con cámaras laterales absidadas; el empleo de alzados de tapial "en un edificio de culto con pavimento de mosaico, cuando otras edificaciones públicas de la ciudad están reutilizando en estos mismos momentos la cantería de expolio de los edificios romanos en sus alzados" (Sánchez Ramos, 2010: 51); la exigua utilización en la península ibérica de una especie de iconostatis de fábrica para cerrar el crucero (cuyos soportes no están alineados), y la ausencia de datos relativos a la cubrición del inmueble.

\section{d) Construcción de funcionalidad desconocida vinculada a las élites}

A la espera de futuras excavaciones que permitan aclarar las dudas que persisten, el análisis tanto de la heterogénea información disponible, como de las hipótesis planteadas hasta ahora nos invita a puntualizar y reflexionar algunas de las argumentaciones esgrimidas. Es por ello que planteamos una nueva hipótesis basada en el análisis crítico y la contextualización de la documentación a la que hemos tenido acceso.

En primer lugar, el registro arqueológico atestigua la construcción, en un momento indeterminado, de un espacio ornamentado con el mosaico con decoración
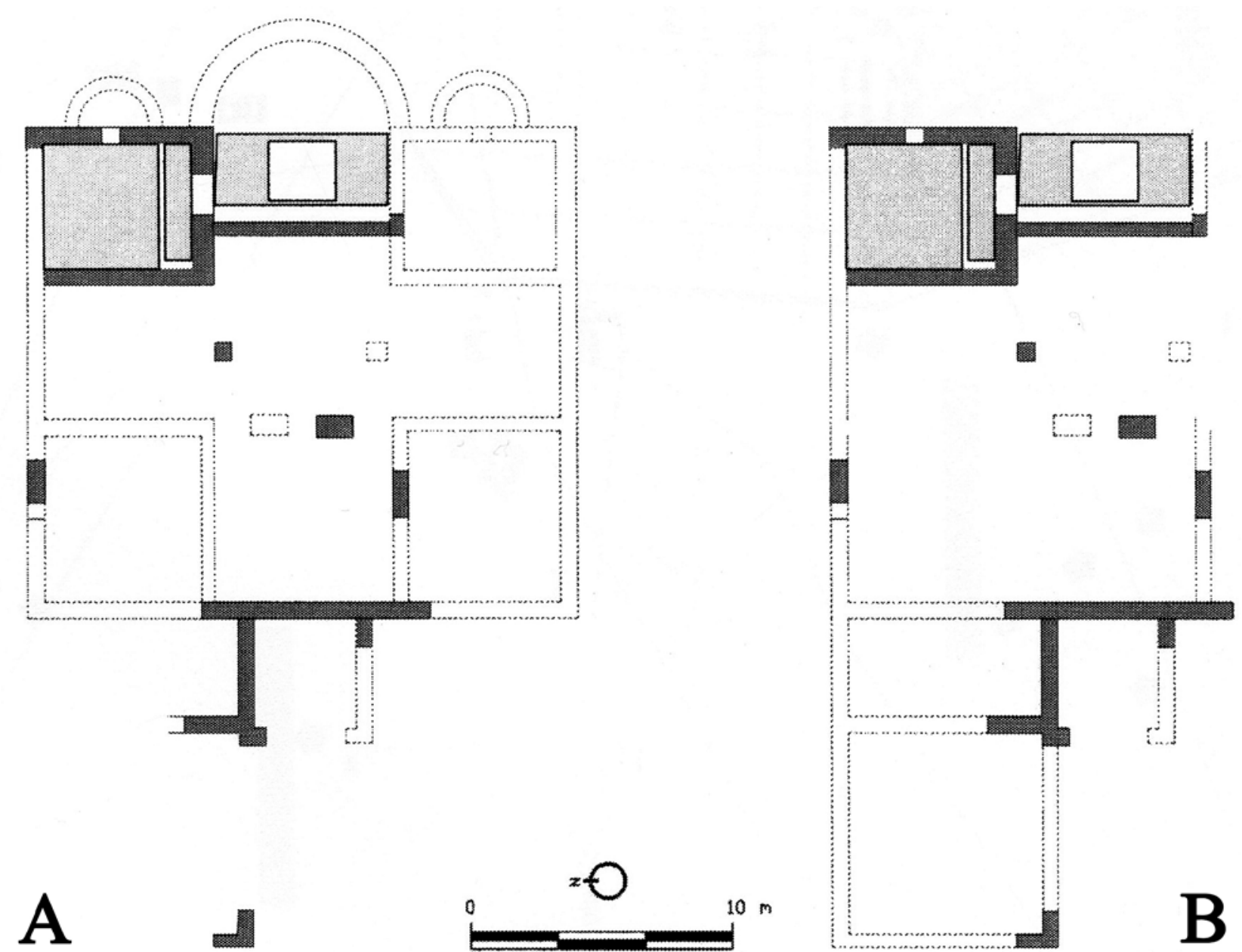

Fig. 4. Córdoba (antigua iglesia de Santa Catalina): planta hipotética de las tardoantiguas descubiertas según $P$. Marfil (A) e I. Sánchez Ramos (B). Modificado a partir de Sánchez Ramos, 2010: fig. 16. / Córdoba (former church of Santa Catalina): hypothetical floor plan of the late antique archaeological remains according to P. Marfil (A) and I. Sánchez Ramos (B). Modified from Sánchez Ramos, 2010: fig. 16. 
geométrica y vegetal descubierto en el corte 9 ( vid. apdo. 2.2). Este pavimento, de cronología indeterminada pero presumiblemente anterior al siglo VI, fue seccionado y destruido parcialmente en su extremo septentrional por un muro que delimitaba el lado sur de una estancia cuadrangular, tal y como se puede observar tanto in situ, como en la documentación fotográfica conservada (fig. 3B). Esta nueva habitación cuadrangular (engalanada con un pavimento musivo polícromo), estuvo delimitada por paramentos con zócalo de sillería y alzado de tapial, y con una cubierta a base de tegulae. Dicha cubrición la conocemos gracias a la U.E. 902 (corte 9). Se trata de un estrato de unos 0,15-0,20 m de potencia que contenía tegulae procedentes presumiblemente del tejado (Penco, 2000: 250; 2002: 8).

El material cerámico contenido en el tapial de los muros indicaría que este ambiente se levantó en un momento indeterminado del siglo $\mathrm{VI}^{11}$, tal y como también ha defendido $\mathrm{M}^{\mathrm{a}}$. A. Utrero (2008: 204; 2009: 143). Lamentablemente, la determinación del nexo que vinculaba este espacio con los paramentos y pavimentos exhumados en los cortes restantes es una tarea compleja y, hoy en día, inviable por las circunstancias que hemos venido exponiendo. La escasez de la superficie exhumada y la identificación de, al menos, dos fases edilicias distintas, impone cautela a la hora de sugerir una propuesta de restitución en planta. A estas dos fases habría que sumar, como mínimo, una tercera, del siglo VII, cuando han sido datadas por P. Marfil (1996a; 1996b: 36; 1996c: 202), algunas evidencias aisladas. Nos referimos a un estrato de tierra apisonada, a modo de pavimento terrizo de unos $0,10 \mathrm{~m}$ potencia destinado a nivelar el terreno, que ocultó el pavimento de opus vermiculatum (corte 2). También a una "interfacie de suelo" que cubrió los paramentos precedentes (corte 5 ); a un estrato similar al identificado en el corte 2 (cortes 8 y 14) y un pozo encañado (corte 9) cuya apertura supuso la ruptura y destrucción parcial del pavimento con decoración geométrica y vegetal descubierto en dicho corte (fig. 3B). Tales testimonios parecen reflejar una cierta "simplificación" en el aspecto del edificio, más que una reforma y renovación de la iglesia, como tradicionalmente ha venido defendiendo P. Marfil.

La prudencia también debe imperar a la hora de determinar la funcionalidad de las distintas estructuras descubiertas, sobre la que conviene realizar también algunas matizaciones. A la ausencia de elementos litúrgicos inequívocos y de decoración arquitectónica recuperados in situ durante las distintas intervenciones, hay que añadir la considerable distancia a la que se hallaron las piezas puestas en relación con la hipotética iglesia por J. Sánchez Velasco, todas ellas de por si descontextualizadas. Así, el número 3 de la calle Encarnación se encuentra a 30 m en línea recta de la antigua iglesia de Santa Catalina, mientras que las plazas de la Concha y de Jerónimo Páez están a más de 70 y 90 m respectivamente.

También resulta problemático el supuesto carácter martirial de la sepultura in urbe documentada ( vid. apdo. 2.1) pues, dado que un paramento adscrito a la posible iglesia seccionó en dos la tumba, ésta no parece haber estado revestida de gran importancia. Ante tal circunstancia, no es fácil sostener la hipótesis tradicional que defiende la existencia de una iglesia martirial "ya sea erigiéndose sobre o junto a la tumba de un mártir que podría existir aquí dentro de un área cementerial previa a la construcción, o a través de la veneración de las reliquias trasladadas de un santo" (Marfil, 1996c: 208).

En cuanto al esquema compositivo y la simbología del mosaico polícromo que ornamentaba la estancia cuadrangular, el exhaustivo estudio realizado por $\mathrm{F}$. Penco (2000; 2002) deja pocas dudas acerca de su simbología cristiana, y de la influencia bizantina, que no dominio ${ }^{12}$, palpable en las artes decorativas cordobesas. Sin embargo, resulta más difícil afirmar o descartar si el citado pavimento perteneció a una estancia sacra o profana. La presencia de elementos vegetales, aves y recipientes en el interior de círculos grandes y pequeños, tangentes y enlazados, o en los octógonos resultantes de dicho esquema, es un fenómeno frecuente en los mosaicos de determinadas iglesias del siglo VI. No obstante, también documentamos su uso en construcciones profanas (fig. 5A y 5B). Es el caso de un mosaico de finales del siglo III o inicios del IV perteneciente a una rica domus de Roma (Baldasarri, 2011: $49-50$ y 58 ss.), o del pavimento de mediados-segunda mitad del siglo $\mathrm{V}$ localizado en la ciudad griega de Cos, y "non attribuibili a edifici religiosi" (De Matteis, 2004: 215).

A raíz de lo expuesto, no podemos precisar la funcionalidad exacta ni de la habitación ornamentada mediante el mosaico polícromo, ni de la construcción de la que formó parte, ya que pudo tratarse de un edificio religioso (no necesariamente una iglesia) de planta ignota, o de una residencia de un alto cargo eclesiástico o de un aristócrata laico, entre otras opciones. Esta última opción, defendida en los últimos años por diversos investigadores, tampoco está exenta de problemas,

\footnotetext{
${ }^{11}$ El mosaico identificado en los cortes 4 y 9 apareció cubierto por un derrumbe de tapial que debió de proceder del alzado del muro que delimitaba el mosaico por su lado meridional. Dicho nivel aportó varios fragmentos de Terra Sigillata Africana forma $\mathrm{D} 2$ (finales del siglo IV-mediados del VII; Serrano, 2005: 244) y Terra Sigillata Hispánica Tardía Meridional forma 1, forma 2 y forma 9 (ss. IV-V, Orfila, 2009 : 543 ss.) "cuyos elementos más modernos pueden datarse en torno al siglo VI" (Penco, 2000: 251).

${ }^{12}$ Aun cuando hay voces que han planteado la posibilidad de que Córdoba acogiese guarniciones bizantinas permanentes (Rodríguez, 1987: 143), o que estuviese bajo control bizantino entre 552-572 y 579-584 (Marfil, 1996b: 41-42; 1996c: 208; 2000: 161), las últimas hipótesis apuntan a que la presencia imperial se limitó a un simple acantonamiento urbano en el litoral peninsular, con avances episódicos hacia el interior abortados pronto por el poder visigodo (Vizcaíno, 2009: 128).
} 
dada la compleja evolución de la arquitectura residencial aristocrática a lo largo de los siglos V y VI. Durante ambas centurias se asistió al paulatino abandono de los peristilos como centro compositivo y articulador de las viviendas aristocráticas emplazadas en el Mediterráneo, con la consecuente reducción del número de domus de peristilo erigidas en esta centuria (Saradi, 1998: 28; Brogiolo, 2011: 75). Esta desaparición fue paralela a la entrada en escena de un nuevo modelo de residencia nobiliaria que proliferó desde el siglo $\mathrm{VI}$ en adelante. Se trata de inmuebles compactos de planta rectangular, desarrollados en varias alturas (las superiores destinadas a espacios representativos y de aparato, y las inferiores a otras actividades). Sostenidos por refuerzos internos y/o externos, suelen prescindir de un espacio abierto central y tienden a emplazarse en ubicaciones relativamente elevadas. Frente a las pretéritas domus, la documentación disponible parece atestiguar un uso muy limitado de pavimentos de sectile o tesellatum (Santangeli, 2011: 30-32, 75 ss. y 134-137; Perich, 2014: 169, 175, 228-233 y 251). Nos encontramos ante un reducido empleo al que aún no se ha podido dar respuesta. Si para A. Perich (2014: 230) "es podria especular sobre la falta de necessitat, d'interès, de recursos econòmics, d'artesans especialitzats, la mala preservació o d'un canvi generalitzat a nivell cultural", R. Santageli (2011: 88) considera que "il dato è tuttavia da considerare con cautela, tenendo conto che la nostra conoscenza archeologica di queste strutture è in tutti i casi limitata al piano terreno, che, come si è visto, era adibito a funzioni di servicio o a staIla, mentre sconosciuto è il piano superiore, destinato ad abitazione e nel quale, quindi, si sarebbero dovuti trovare gli eventuali elementi decorativi".
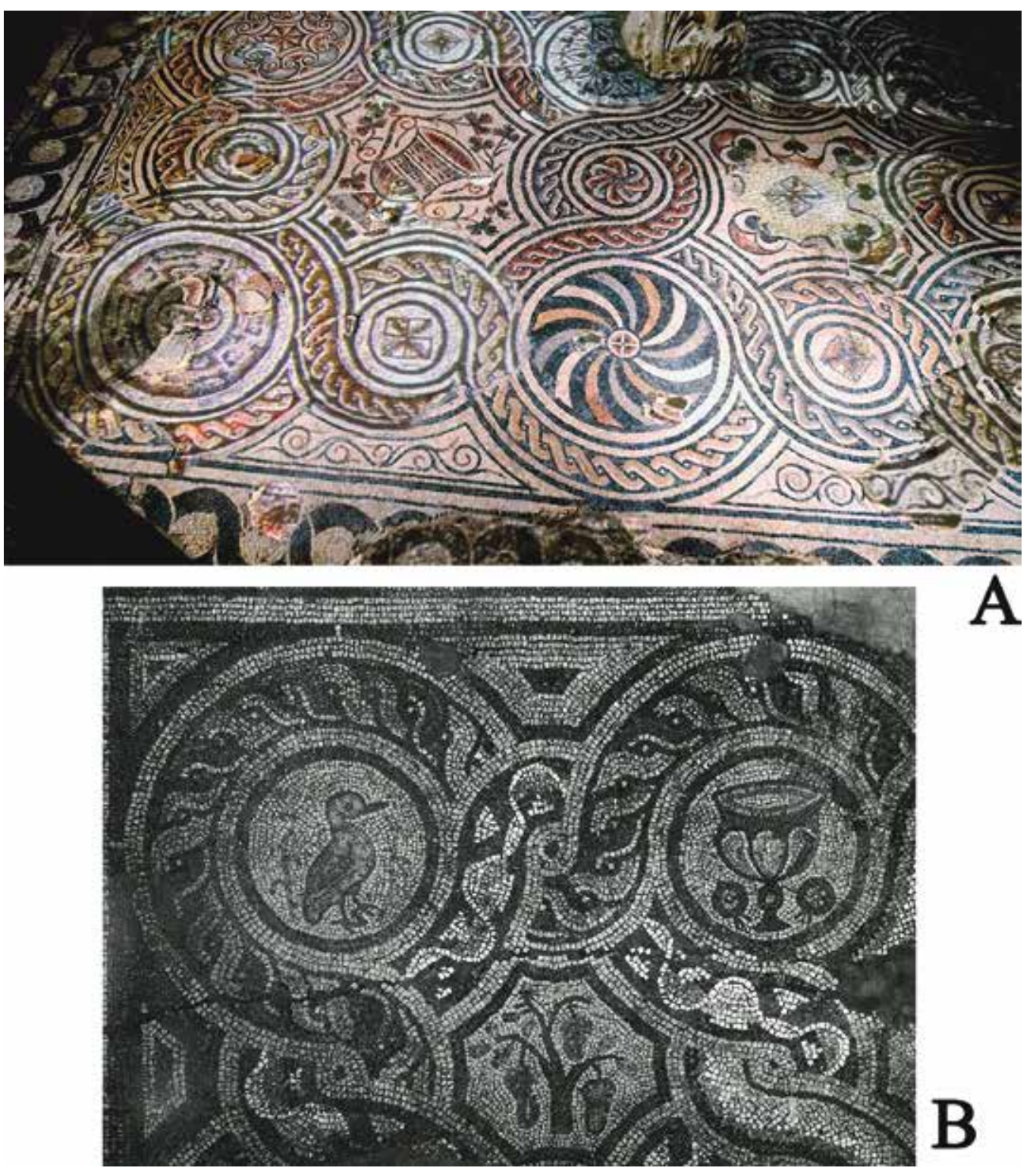

A

Fig. 5. A. Roma (palacio Valentini): estado actual y restitución infográfica del mosaico. Fuente www. palazzovalentini.it/. B. Cos (barrio portuario): detalle del mosaico (De Matteis, 2004: lám. 14). / A. Roma (Valentini palace): current state and infographic restitution of the mosaic. Source: www.palazzovalentini. it/. B. Cos (port district): detail of the mosaic (De Matteis, 2004: lam. 14). 
En el supuesto caso de que las estructuras cordobesas a las que nos referimos pertenezcan a una edificación doméstica, es posible que nos encontremos ante una domus cuyos espacios de representación se emplazaron en la planta baja, al estilo de las antiguas casas unifamiliares aristocráticas que caracterizaron a las ciudades romanas hasta el siglo V. Esta es una hipótesis problemática, dado que en Hispania no conocemos con seguridad ni una sola domus urbana construida o monumentalizada en la sexta centuria ${ }^{13}$. Dicho vacío es especialmente llamativo en las ciudades de la Spania bizantina (Carthago Nova, Malaca, Septem, etc.) puesto que "todo cuanto conocemos de edilicia residencial nos deja ver una imagen de humildad manifiesta, lejos del lujo y la suntuosidad que aún conservan mansiones urbanas del tipo de las cirenaicas, donde se mantiene la regularidad, producciones musivas, etc. De esta forma, se desprende también una gran simplicidad en la estructura, lejana a la diversidad de modelos que podemos encontrar en otras áreas como la palestina" (Vizcaíno, 2009: 387). Esta realidad contrasta con la de otras urbes mediterráneas bajo control de Bizancio (Antioquía, Apamea, Argos, Hermíone ${ }^{14}$, etc.), donde sí hay evidencias de viviendas decoradas con mosaicos fechados en el siglo VI, cuando tuvo lugar su edificación o reforma (Baldini, 2001: 133, 138, 142, 145, 214).

Con independencia del tipo de inmueble al que responda el caso que nos ocupa, es evidente que su ubicación no fue escogida al azar. Fue erigido junto al ramal oriental del antiguo kardo maximus y al noreste del complejo episcopal, que en pleno siglo VI seguía ornamentándose con ricos mosaicos (Sánchez Ramos, 2009). Dicha realidad la conocemos gracias a las intervenciones practicadas en la década de 1930 bajo la mezquita fundacional de 'Abd al-Raḥmān I. Destaca el hallazgo de una estancia delimitada por muros de opus vittatum mixtum y decorada con un mosaico "con representación de cenefas de plantas afrontadas, de cráteras y de otros motivos geométricos que se encuentran inscritos dentro de panales, de los que in situ se reconocen tan sólo tres de forma parcial" (Sánchez Ramos, 2009: 134). Esta construcción ha sido fechada en el siglo $\mathrm{VI}$ a raíz de la utilización de ladrillos con la inscripción Ex off(icina Leonti (crismón) (C.I.L II/7², 698; siglos VI-VII) en los paramentos, así como por las propias relaciones estratigráficas: los muros y el mosaico aparecen unidos entre sí mediante boceles de media caña, lo que apunta hacia una "construcción que responde probablemente a una única fase" (Sánchez Ramos, 2009: 134).
El poder de atracción del grupo episcopal y del complejo civil aledaño (además de la cercanía del río Guadalquivir) no solo permite entender el expediente constructivo identificado en calle Rey Heredia 20, sino también varias estructuras (públicas, semipúblicas y privadas) que proliferaron al norte y al noreste del centro de poder de Corduba y que se alternaron en el espacio con otros testimonios de menor entidad, como pozos negros o muladares (Ruiz Bueno, 2016: 549, 594, 668 ss. y 723-725).

\subsection{Fase emiral (SS. VIII-IX)}

Tras una fase de cierta degradación de las estructuras tardoantiguas localizadas bajo la antigua iglesia de Santa Catalina, correspondiente al siglo VII, su inutilización definitiva fue fechada por Marfil en el siglo VIII (Marfil, 1996a; 2000: 171). Este fenómeno ha quedado reflejado en la evolución de algunas superficies de tránsito, como el mosaico polícromo, oculto bajo un nivel arcilloso y compacto (corte 9); un suelo del siglo VII cubierto por un estrato de color castaño oscuro y consistencia media (corte 5), y por último, un pavimento de opus vermiculatum, afectado por una fosa que llegó a alcanzar a la tumba de los siglos IV-V (corte 2). Con posterioridad, pero en esta misma centuria, se produjo el colapso de los alzados de tapial de los paramentos localizados en los cortes 2 y 9 , por lo que la integridad estructural de las construcciones tardoantiguas debió verse seriamente comprometida. Por el momento, la información arqueológica disponible no permite dilucidar qué tipo de ocupación hubo en este solar durante el Emirato. Se trata de un problema extensible en gran medida al entorno inmediato, donde tan solo podemos reseñar la ocupación doméstica identificada en el antiguo teatro. En esa zona, en los siglos VI-VII se configuró un barrio residencial de nueva planta, articulado mediante rampas y terrazas, que continuó habitado en época emiral (Monterroso y Cepillo, 2002: 161-168).

\subsection{Fase califal (SS. X-XI)}

Al contrario de lo que sucede con las fases anteriormente citadas, la interpretación de las estructuras que van a ocupar este solar a partir de la llegada del Califato no presenta ningún género de dudas. El inmueble que se erigió en este solar a partir de la proclamación del Califato, y que todavía puede verse en pie aún con muchas transformaciones, fue identificado ya en 1627 por Pedro Díaz de Ribas como una pequeña mezquita

\footnotetext{
${ }^{13}$ Para la segunda mitad del siglo V sí disponemos de algunos ejemplos. En Hispalis tenemos la "casa del Sigma", una vivienda aristocrática dotada de un espacio de representación rematado en ábside (que incluía un stibadium) y que perdió su carácter aristocrático en torno a 525 530 (García, 2012: 904); mientras que en Complutum, destaca la "casa de Cupidos", ornamentada con nuevos mosaicos en la segunda mitad de la quinta centuria (Rascón y Sánchez, 2015: 211).

${ }^{14} \mathrm{En}$ la "Casa in od. Zoodochios Pigis-A. Syngrou" tenemos constancia de mosaicos de finales del siglo VI entre los que destaca uno en el que aparecen representados "motivi geometrici, pavoni ai lati dell'Albero della Vita, pannelo con equidi affrontati ai lati di un kantharos" (Baldini, 2001: 214).
} 
(Marfil, 1996a). Pese a que el inmueble ha sido objeto de numerosos análisis e intervenciones arqueológicas a lo largo del tiempo, y a pesar de que su interpretación como mezquita nunca se ha puesto en duda, lo cierto es que aún se desconocen muchos de sus detalles constructivos y de su evolución debido, sobre todo, al mal estado de conservación de las estructuras, a la desconexión entre los estudios dedicados a este complejo, a la difícil accesibilidad a los resultados de algunas de las intervenciones efectuadas, y a la falta de publicaciones derivadas de las mismas.

Si bien autores como L. Ma Ramírez de las Casas Deza, R. Ramírez de Arellano o R. Castejón comenzaron a citar este inmueble en sus trabajos, éste no fue protagonista de ningún análisis en profundidad hasta las publicaciones de V. Escribano (1964-65) y F. Hernández (1975). El mérito principal de estos autores reside en su capacidad para esbozar la organización general del edifico y su posible cronología, que trataremos a continuación, basándose casi exclusivamente en la observación de las estructuras conservadas. Ambos autores propusieron sendos planos de la construcción islámica (Escribano, 1964-65: 89; Hernández, 1975, 204: fig. 43) que, hasta la fecha, han sido los únicos disponibles para ilustrar acerca de la posible estructuración de la mezquita.

El subsuelo del solar permaneció intacto hasta el último tercio del siglo XX, momento en que investigadores como L. Olmo (1981) o P. Marfil (1996a) realizaron excavaciones que confirmaron la morfología general del edificio vislumbrada por Escribano y Hernández. No obstante, el alcance de sus conclusiones con respecto a esta fase nos resulta difícil de calibrar, dado que aún no hemos tenido acceso a la totalidad de la información recuperada en estas intervenciones ${ }^{15}$. Por último, cabe citarse el estudio arquitectónico dirigido por L. Caballero (Caballero et al., 2007), que valoraremos en lo sucesivo.

\section{a) Estructura general y tipología de la mezquita}

A simple vista resulta sencillo confirmar que nos encontramos ante una mezquita exenta, dotada de contrafuertes y compuesta por dos partes principales: un oratorio de tres naves, y un patio al aire libre con un alminar en su esquina noreste. Paradójicamente, aunque se han sucedido multitud de intervenciones en el seno de este edificio, no han conducido, necesariamente, a un mejor conocimiento de la estructura del mismo. Tanto es así que las dimensiones perimetrales de cada uno de las partes principales consignadas por los distintos autores no siempre coinciden, albergando en ocasiones diferencias muy notables para un mismo parámetro (vid. González Gutiérrez, 2016a: 184, tabla 11; 187, tabla 12). Por esta razón, para aportar una planta de la construcción islámica actualizada ha sido necesario conjugar las medidas registradas por los distintos autores con aquellas que hemos podido tomar in situ. Así, proponemos una planta para la mezquita (fig. 6) que, aunque provisional, nos permite realizar algunos análisis comparativos que redundan en un mejor conocimiento de su tipología y aspecto general.

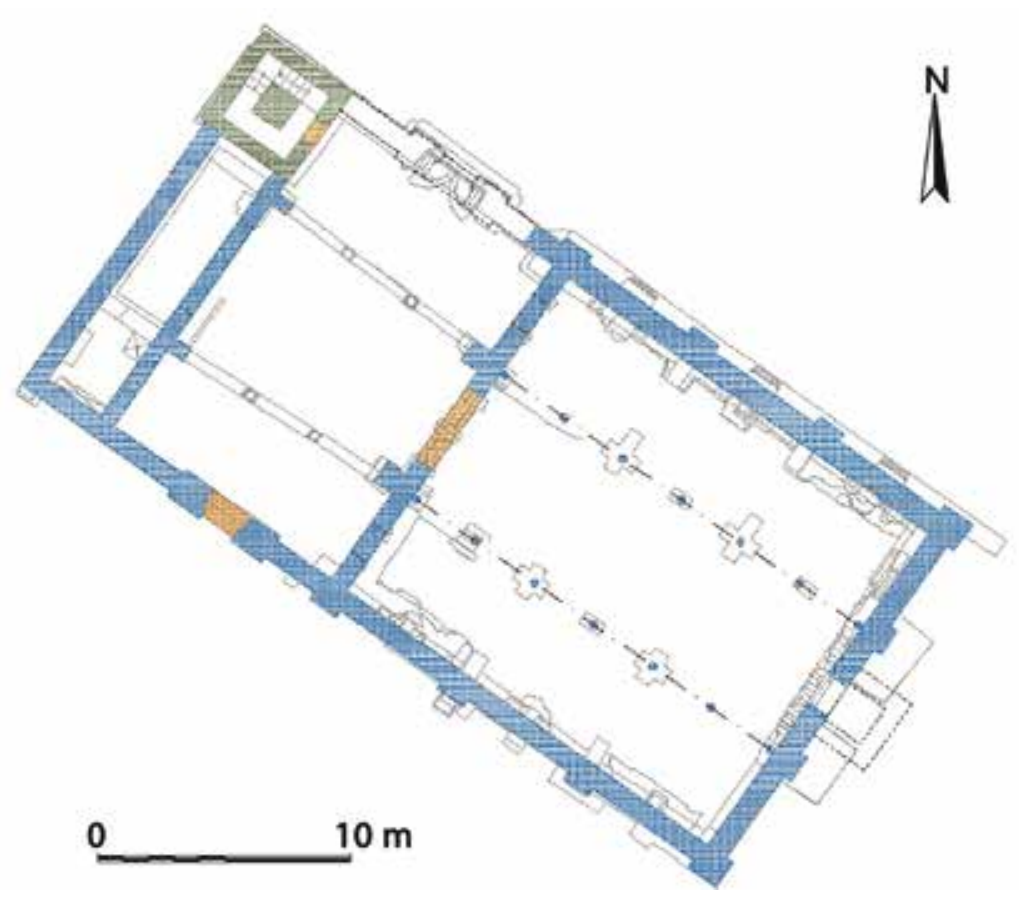

Fig. 6. Córdoba (antigua iglesia de Santa Catalina): planta de la mezquita según los restos arqueológicos recuperados y conservados. Reelaborado a partir de observaciones propias, así como de los datos contenidos en Escribano, 1964-1965; Hernández, 1975; Marfil, 1996a, y Caballero et al., 2007. / Córdoba (former church of Santa Catalina): floor plan of the mosque according to the recovered and conserved archaeological remains. Redrawing based on our own observations and the information contained in Escribano, 1964-1965; Hernández, 1975; Marfil, 1996a, and Caballero et al., 2007.

\footnotetext{
${ }^{15}$ Recordemos que no hemos podido acceder al informe de Olmo. La información que conocemos de esta intervención es gracias a P. Marfil (1996a) y a L. Caballero et al. (2007). Contamos también con información extraída de algunas entrevistas orales con estos arqueólogos.
} 
A la luz de este plano es posible comprobar que la planta de la mezquita objeto de estudio guarda similitudes muy estrechas con otras masāŷid documentadas en Córdoba (fig. 7), muy especialmente con la denominada mezquita de Fontanar (Luna y Zamorano, 1999; González Gutiérrez, 2016a: 109 ss.). Se trata de mezquitas que se trazan a partir de formas cuadradas que se duplican: las salas de oración, de planta cuadrada, van acompañadas de patios porticados en su lado noroeste, también de forma cuadrangular, y de superficie igual o ligeramente mayor a las de las salas ${ }^{16}$. Es una tipología que emula, a grandes rasgos, el esquema de doble cuadrado que se sigue en la aljama cordobesa en época califal (vid. González Gutiérrez, 2016a: 309-311; 2017: 5-6).

Pese a que la mezquita sita en la calle Rey Heredia pertenece a esta tipología, ostenta una pequeña particularidad que la diferencia del resto de casos incluidos en la misma. Como puede apreciarse en la fig. 7, en Fontanar, la estación de autobuses y las Naves de Fontanar, las salas de oración y los patios dibujan cuadrados de idénticas dimensiones, quedando fuera el pórtico adosado al lado noroeste del sahn. En cuanto a Santa Clara, la diferencia estriba en que el cuadrado del patio ha de incluir al pórtico para respetar las proporciones marcadas por el haram ${ }^{17}$. Este ajuste se debió, muy posiblemente, a la necesidad de encajar esta tipología arquitectónica en un solar que presentaba unas condiciones muy específicas, ya que se encontraba ocupado con anterioridad y condicionado por el urbanismo circundante ${ }^{18}$.

\section{b) La sala de oración}

El estado actual del espacio que funcionó como sala de oración presenta múltiples reformas, restauraciones y modificaciones, efectuadas progresivamente y con desigual criterio. Por ello, para intentar dilucidar cómo fue este haram vuelve a ser necesaria la combinación de los datos recuperados a lo largo de los años con la información obtenida a través de la observación directa de los restos.
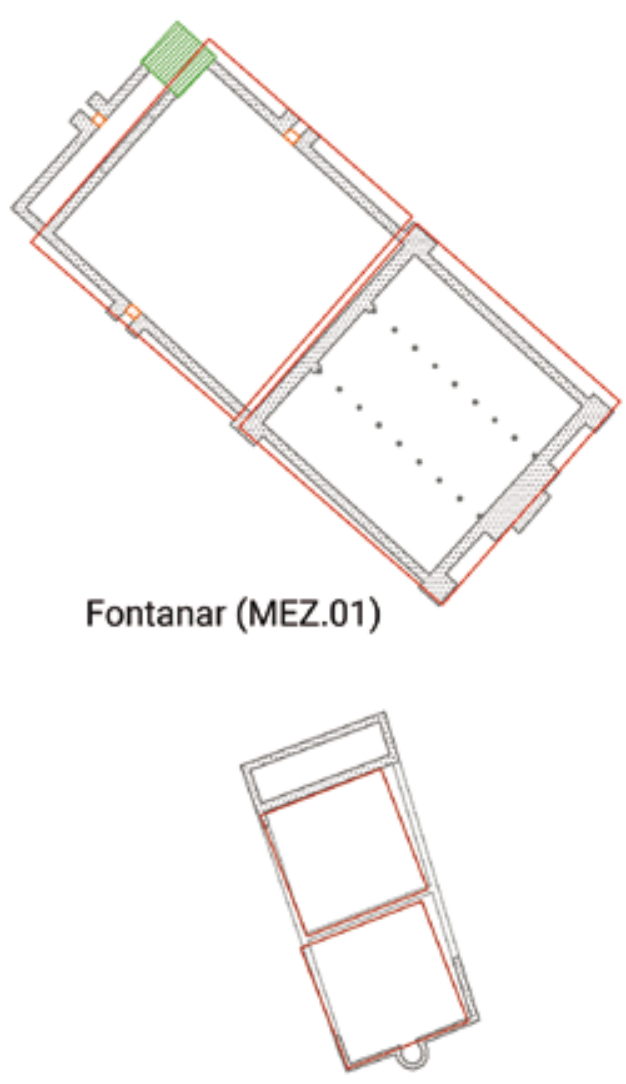

Estación de autobuses (MEZ.02)

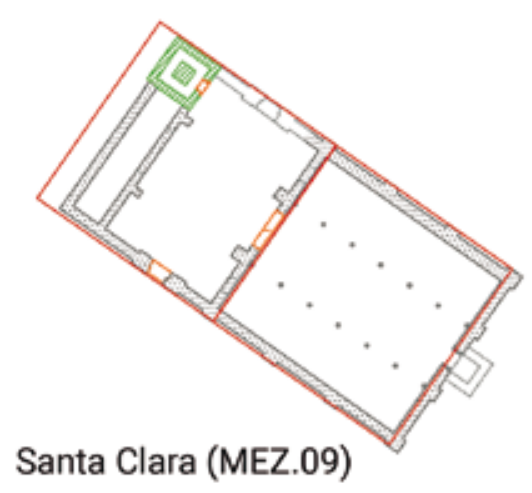

Santa Clara (MEZ.09)

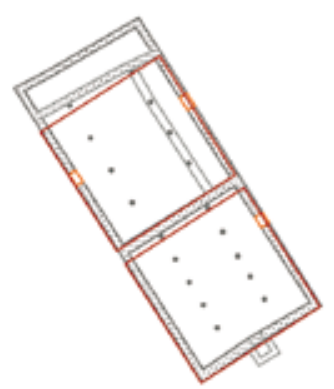

Naves de Fontanar (MEZ.15)
Fig. 7. Córdoba. Mezquitas que parecen responder al tipo de doble cuadrado califal identificado para Córdoba tras los análisis de metrología (González Gutiérrez, 2016b: 277, fig. 3). / Córdoba. Mosques that seem to correspond to the caliphal double-square typology identified for Córdoba after the metrology analyses (González Gutiérrez, 2016b: 277, fig. 3).

\footnotetext{
${ }^{16}$ Se trata, en definitiva, de la tipología de doble cuadrado califal identificada para Córdoba y recientemente publicada en González Gutiérrez, 2017.
} 
La sala de oración, de planta cuadrangular, estuvo organizada al interior en tres naves perpendiculares a la quibla, que se conserva hasta una altura de $7,5 \mathrm{~m}$ (Caballero et al., 2007: 18). Contó con un mihrab en su eje axial, esto es, justo frente a la nave central, del que solo subsiste la delimitación del alfiz que habría enmarcado su arco de entrada (vid. Caballero et al., 2007: 39, figs. 26 y 27). No ha quedado tampoco ninguna pista que nos ilustre acerca de la posible planta que pudo tener este mihrab. La nave central era ligeramente más ancha que las laterales (unos $6 \mathrm{~m}$ para la primera frente a, aproximadamente, 4,5 $\mathrm{m}$ para las otras dos), al igual que sucede en la mezquita de Fontanar (Luna y Zamorano, 1999). Cada nave se dividió en seis tramos, de unos $3 \mathrm{~m}$ de largo cada uno, aunque probablemente los del remate tuviesen unas dimensiones algo menores.

La información arqueológica disponible en la actualidad no permite hablar de la existencia de puertas que diesen acceso directo al oratorio desde el exterior ${ }^{19}$, por lo que la entrada debió efectuarse a través de otro vano, practicado en el muro de separación con el patio. En dicho muro se aprecian los restos de dos contrafuertes, ubicados en el punto al que llegaban las dos arquerías que separaban las naves del oratorio. Tampoco hemos sido capaces de identificar restos de posibles ventanas o aperturas en los muros de esta sala ${ }^{20}$. La utilización continuada de este espacio a lo largo de los siglos, así como sus constantes cambios de uso, nos impiden conocer qué pavimento y revestimientos parietales tuvo en época islámica. Pese a todo, sí hemos podido comprobar que la cota de suelo de este espacio parece ser ligeramente más alta que la del patio.

Los elementos arquitectónicos con los que se construyeron las arquerías que separan las naves merecen una mención aparte. Dado que la iglesia fundada en este mismo emplazamiento tras la conquista castellana reutilizó, de forma casi íntegra y sin modificaciones, el espacio de la anterior mezquita, resulta complicado diferenciar cuáles de estos materiales se encontraban ya en esta última y qué otros fueron añadidos con posterioridad. M. A. Jordano hace un recuento de los mismos, entre los que destaca un capitel visigodo, tres romanos de orden corintio y dos califales. Esta autora incide en la complejidad que entraña precisar cuáles se encuentran aún en su emplazamiento original y cuáles fueron trasladados (Jordano, 2002: 41-43).

Al exterior, las fachadas de la sala de oración contaron con cuatro contrafuertes cada una, que se unían en las esquinas. Pese a que su identificación y medición resulta ardua debido a las constantes modificaciones experimentadas por este edificio, parece tratarse de contrafuertes no estructurales, sino representativos. La mayoría se encuentran muy deteriorados, presentando algunos incluso recubrimientos posteriores. Del muro noreste, que se conserva hasta su remate gracias a obras de restauración (Caballero et al., 2007: 19) tan solo conserva el contrafuerte de la esquina, que se habría unido al de la esquina de la quibla.

El estado de conservación de los alzados está bastante alterado, por lo que el aspecto que presentaban en época islámica apenas puede adivinarse en este tramo. En la fachada noreste correspondiente al oratorio, en su cara externa (calle Rey Heredia), no han quedado piezas pertenecientes a la época islámica, ya que el muro fue desmontado y rehecho en su totalidad (Caballero et al., 2007: 19). En la fachada suroeste (calle Osio) sí pueden distinguirse algunos sillares islámicos, almohadillados, con unas dimensiones generales de $1 \mathrm{x}$ $0,36 \mathrm{~m}$ (longitud por altura), y con alternancia irregular entre sogas y tizones (fig. 8).

\section{c) El patio}

El patio o sahn, anexo al lado norte de la sala de oraciones, tuvo un tamaño ligeramente menor que ésta (aproximadamente, $15 \times 17 \mathrm{~m}$ ). Se accedía a él a través de un vano existente en el muro de separación que compartía con el oratorio. De dicho muro tan solo se han documentado tres hiladas de cimentación, de las cuales la tercera marca el umbral de la puerta. No podemos extraer datos referentes al posible aspecto de la fachada hacia el patio, pues se encuentra muy modificada por las diversas reutilizaciones a lo largo de los siglos, así como por la erosión y los derrumbes.

Desde la calle, se entraba al sahn por una puerta ubicada en el muro suroeste, de 1,5 x $3 \mathrm{~m}$. Se enmarcaba en un arco de herradura falso, tallado en la sillería y en las dovelas, cuyo alfiz estuvo rehundido en ambas caras. Todo este conjunto debió de estar decorado, por dentro y por fuera, por distintas piezas que se empotrarían en los sillares, aunque del alfiz tan solo se han conservado su impronta y los retalles para el empotrado de su decoración (Jordano, 2002: 45-46; Caballero et al., 2007: 19 y 27; fig. 9). Aunque no han quedado evidencias contundentes, se presume que enfrentada a esta puerta habría existido otra de características similares, en el muro noreste. M. A. Jordano (2002: 45-46) considera que esta puerta tiene una adscripción claramente califal, quizás de al-Hakam II.

\footnotetext{
${ }^{17}$ Planta de aproximadamente $18 \times 19 \mathrm{~m}$ (ancho x longitud), considerando las medidas exteriores. Ello dejaría una superficie útil interior de 264,95 m². ${ }^{18}$ Esto no ocurría en los otros tres casos, construidos en zonas hasta entonces baldías, libres de restricciones urbanísticas previas.

${ }^{19} \mathrm{Al}$ este del mihrab es posible distinguir una puerta, pero pertenece a un momento posterior (Caballero et al., 2007: 61).

${ }^{20}$ Las circunstancias de nuestra observación al interior no fueron las más adecuadas para distinguir este tipo de huellas, sobre todo por la oscuridad general y por el difícil acceso a las distintas partes de la estructura del edificio. Por fuera, las fachadas acusan tantos parches, reparaciones e intervenciones que dificultan incluso la distinción de los sillares islámicos. En cualquier caso, ninguno de nuestros predecesores hace mención a este tipo de elementos.
} 

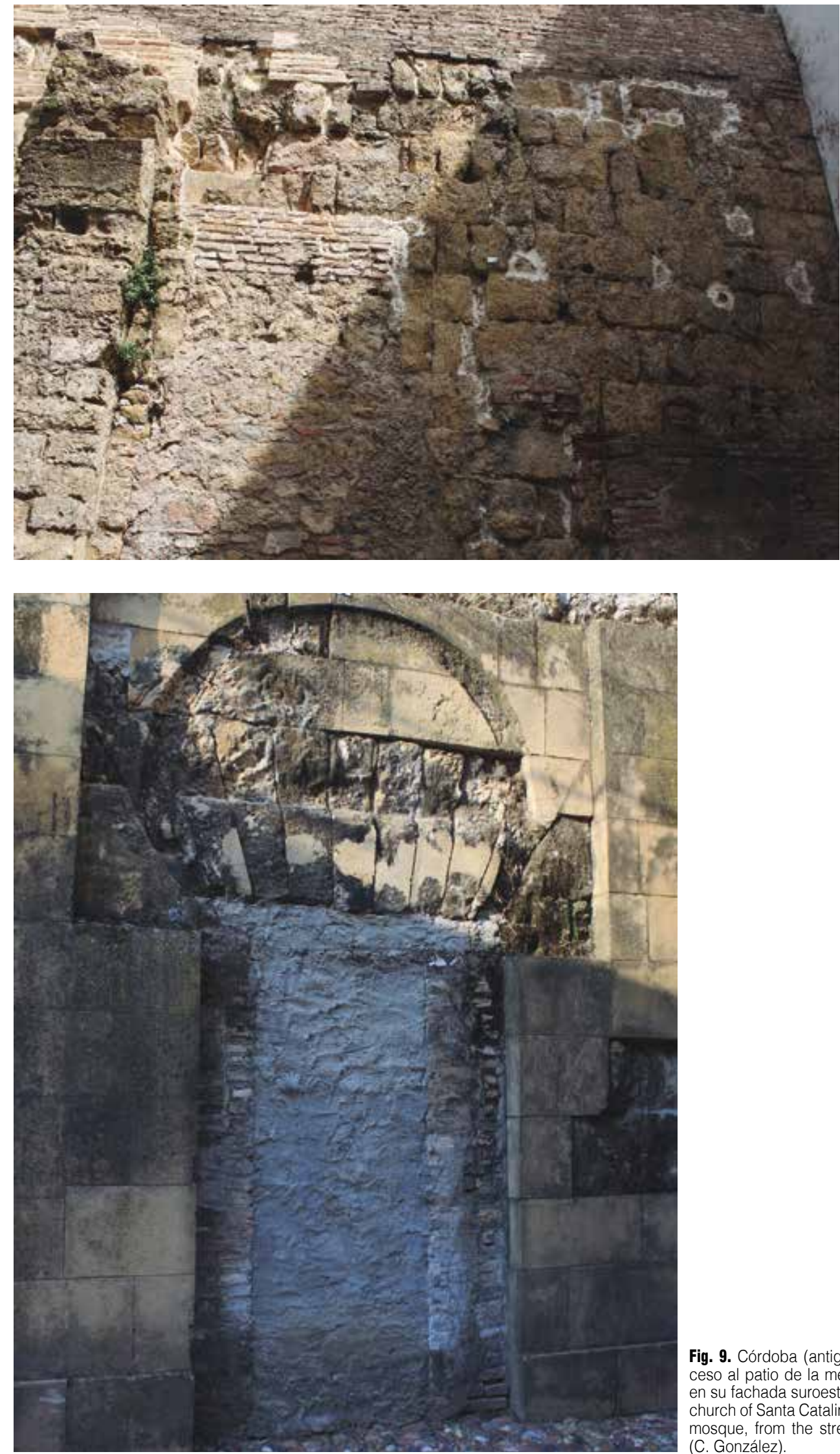
(C. González).
Fig. 8. Córdoba (antigua iglesia de Santa Catalina): vista exterior del muro suroeste, en su tramo correspondiente a la sala de oraciones (C. González). / Córdoba (former church of Santa Catalina): external view of the south-west wall, in its section belonging to the prayer room (C. González).

Fig. 9. Córdoba (antigua iglesia de Santa Catalina): acceso al patio de la mezquita, desde la calle, practicado en su fachada suroeste (C. González). / Córdoba (former church of Santa Catalina): entrance to the courtyard of the mosque, from the street, located in the south-west wall 
La falta de precisión de algunas de las intervenciones arqueológicas desarrolladas en este inmueble, así como la desconexión entre ellas, impiden conocer con claridad cuántos pórticos tuvo este patio, y cómo eran. El estudio de L. Caballero concluye que existió, al menos, una galería o pórtico adosado al lado noroeste del patio, que se entregaba al alminar (ubicado en el ángulo noreste del conjunto), y que pudo estar abierto al patio a través de arcos. De este pórtico, afirma Caballero, se conservan algunos restos de sus cimientos, que se disponen paralelos tanto a este muro de fachada como al lado sureste del alminar (Caballero et al., 2007: 19), aunque no son visibles en la actualidad. Algunos investigadores han planteado la existencia de otras dos galerías porticadas, para los lados este y oeste del patio, si bien las excavaciones arqueológicas desarrolladas hasta la fecha no parecen haber sido capaces de confirmarlo o refutarlo (Caballero et al., 2007: 19). A este respecto, S. Calvo (2014: 582) apunta que la existencia de tres galerías porticadas habría reducido en exceso el espacio útil del patio, y considera que las arquerías laterales que se pueden apreciar en la actualidad se construyeron en un momento posterior, bajo el dominio cristiano. (fig. 10).

Con respecto a su aspecto exterior, y a pesar de las múltiples fases y alteraciones experimentadas por el edificio, aún hoy pueden observarse vestigios de alzados islámicos, especialmente en su fachada suroeste (calle Osio). Aquí puede apreciarse la labra almohadillada de los sillares, que tienen unas dimensiones generales de $1 \times 0,35 \mathrm{~m}$. A su vez, la altura de las hiladas oscila entre los 35 y los 38 centímetros (fig. 11). En el muro de cierre noroeste de la mezquita también pueden observarse algunos sillares fechables colocados a soga y tizón y almohadillados, si bien presentan un enorme grado de erosión (fig. 12).

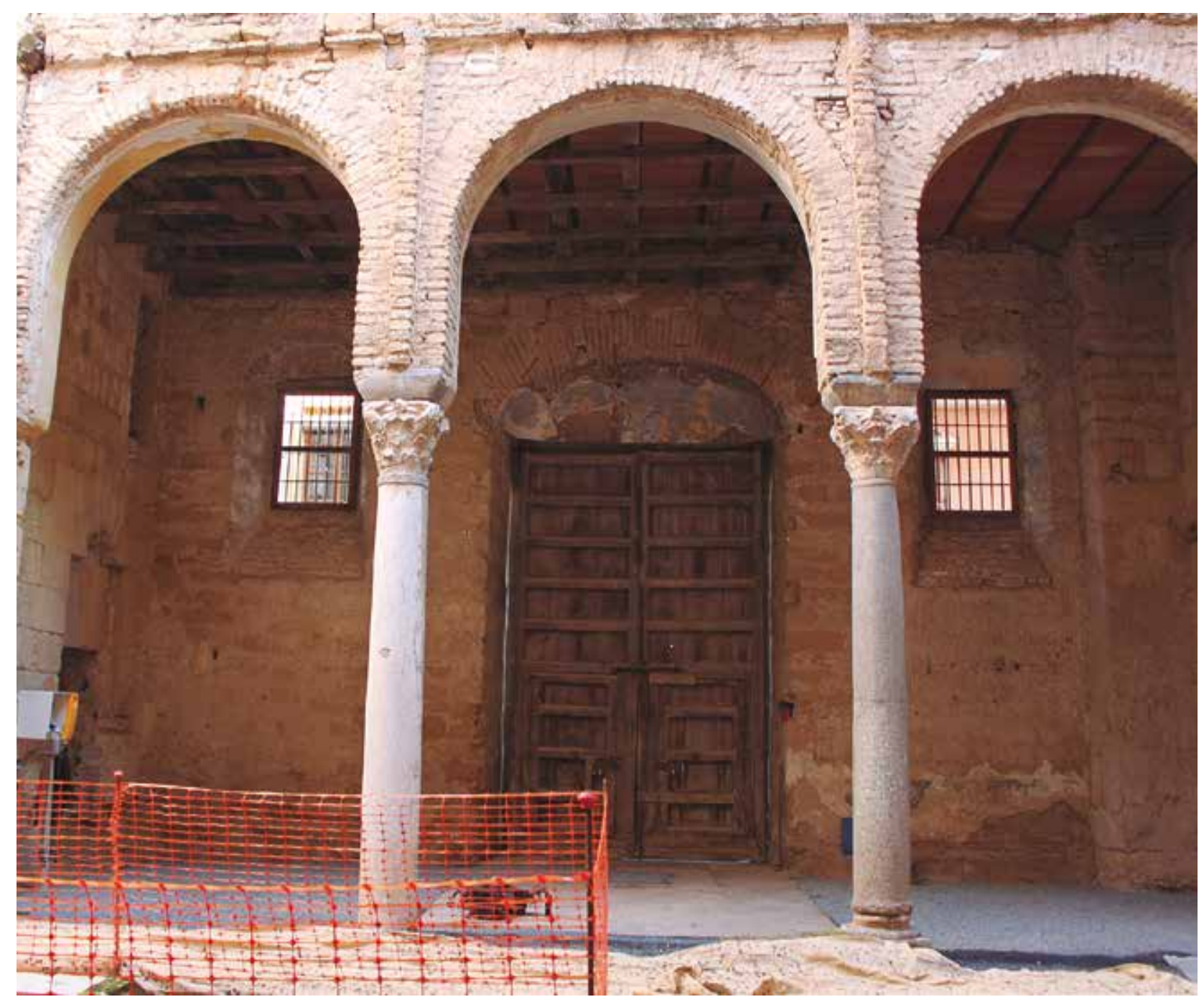

Fig. 10. Córdoba (antigua iglesia de Santa Catalina): interior del patio. La galería porticada que discurre paralela al muro NE de fachada del edificio, y que tiene una simétrica enfrente, ha llevado a pensar en la posibilidad de que el patio de la mezquita contase con galerías en todos sus lados (C. González)./ Córdoba (former church of Santa Catalina): interior of the courtyard. The portico arranged parallel to the north-east wall of the building, which has a twin in the opposite side, has led to think that this courtyard could have been provided with porticoes in all its sides (C. González). 


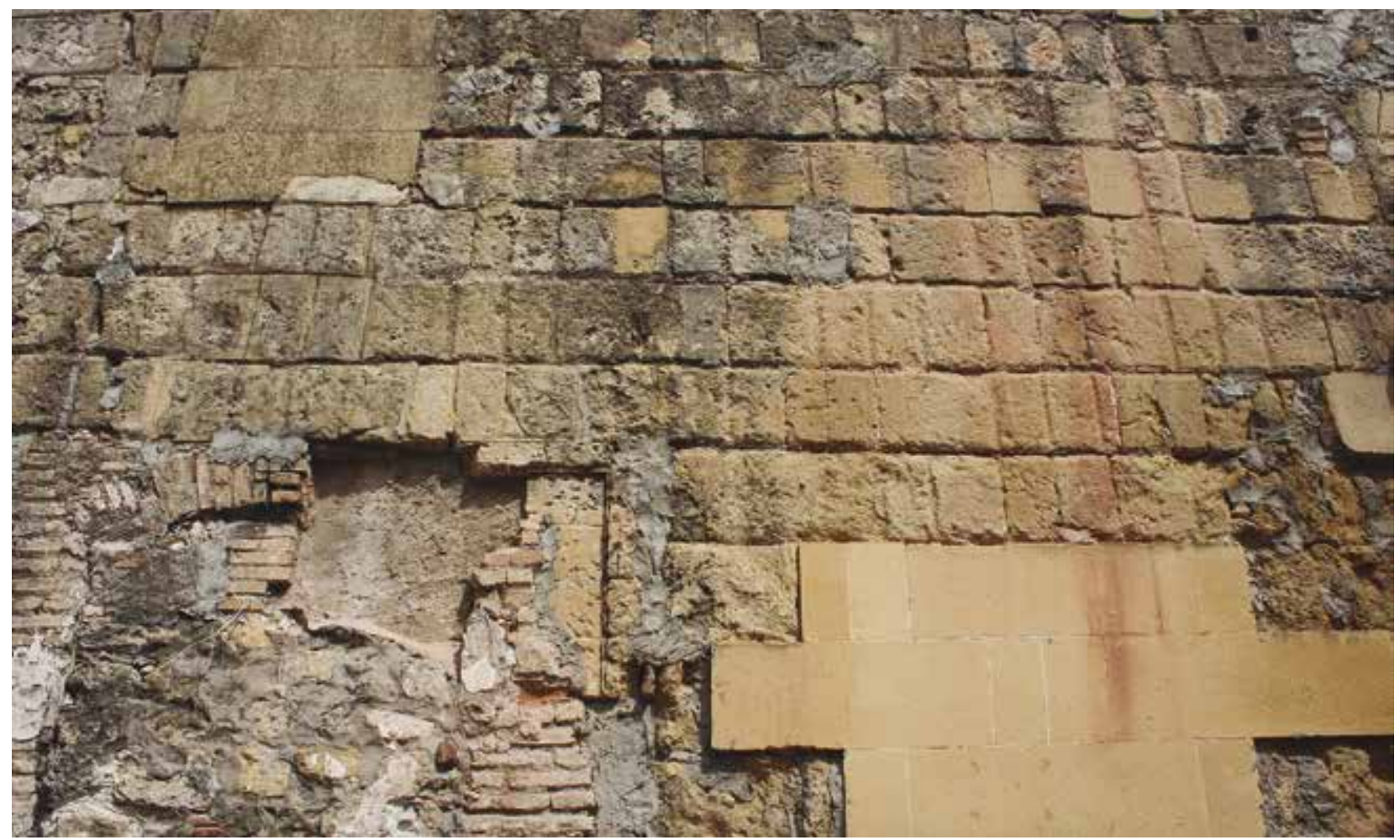

Fig. 11. Córdoba (antigua iglesia de Santa Catalina): vista exterior del muro suroeste en su tramo correspondiente al patio de la mezquita, donde se distingue la labra almohadillada de los sillares (C. González). / Córdoba (former church of Santa Catalina): external view of the southwestern wall, in its section belonging to the mosque's courtyard. It can be observed the padded cut in the stone blocks (C. González).

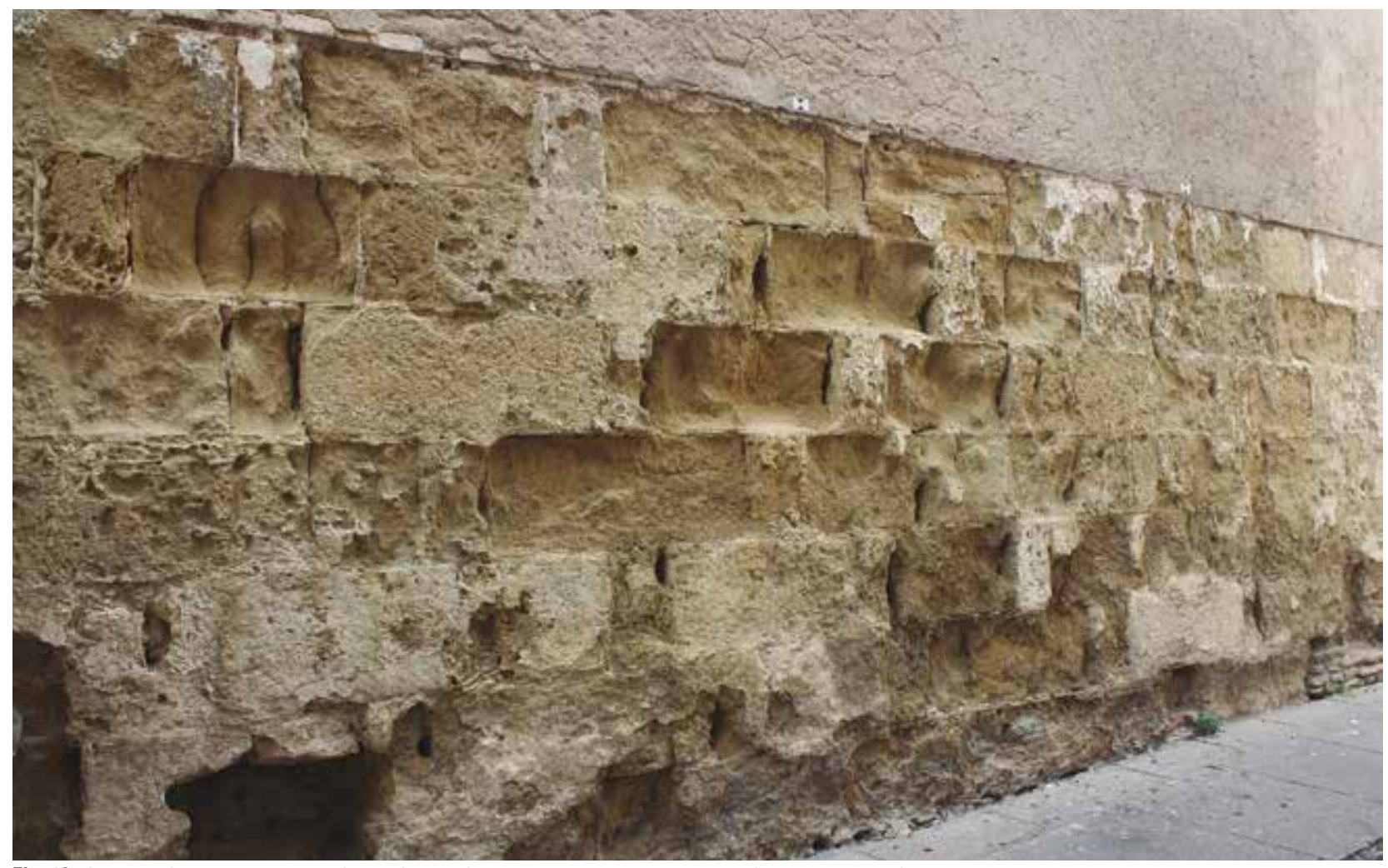

Fig. 12. Córdoba (antigua iglesia de Santa Catalina): vista exterior de las hiladas inferiores que conforman el muro noroeste de la antigua mezquita, en la calle Osio (C. González). / Córdoba (former church of Santa Catalina): external view of the lower line of ashlars belonging to the north-west wall of the former mosque, in Osio street (C. González). 


\section{d) El alminar}

Se trató de una torre de planta cuadrangular de aproximadamente 4,30 m de lado, que sobresalió del patio unos centímetros al exterior (fig. 13A). De la fábrica islámica original se conservan aproximadamente $9 \mathrm{~m}$ de alzado, visibles sobre todo en las fachadas noroeste y noreste, así como un total de veinticuatro hiladas de, aproximadamente $0,40 \mathrm{~m}$ de alto cada una. Se accedía al mismo a través de una puerta adovelada ubicada en su lado sureste, cuyo vano tenía una anchura de 0,90 m y $2 \mathrm{~m}$ de altura (fig. 13B). El interior del alminar se organizó en torno a un machón central cuadrado, de 1,40 m de anchura, en el que se encastraban los escalones, de unos $0,85 \mathrm{~m}$ de longitud, que bordean el machón por su flanco izquierdo. Cada escalón estuvo hecho de un úni- co sillar monolítico de calcarenita, de color amarillento o ceniza, que suele presentar huellas de cincel.

Por último, llama la atención la austeridad de este alminar, que no presenta ninguna ventana, al contrario de lo que parece ser frecuente en otros casos andalusíes (González Gutiérrez, 2016a: 393 ss.). Algunos investigadores que nos precedieron piensan que nunca las tuvo (Escribano, 1964-65: 85; Hernández, 1975: 203 ss.). Otros tan solo se limitan a indicar que la mezquita no conserva, en general, ninguna ventana original (Caballero et al., 2007: 19), si bien advierten de que, con la posterior transformación del edificio en iglesia ${ }^{21}$, la torre se desmochó a la altura de sus ventanas (Caballero et al., 2007: 41). Por tanto, puede ocurir que el alminar sí tuviera ventanas en origen, pero éstas quedaron anuladas con reformas posteriores (fig. 14).
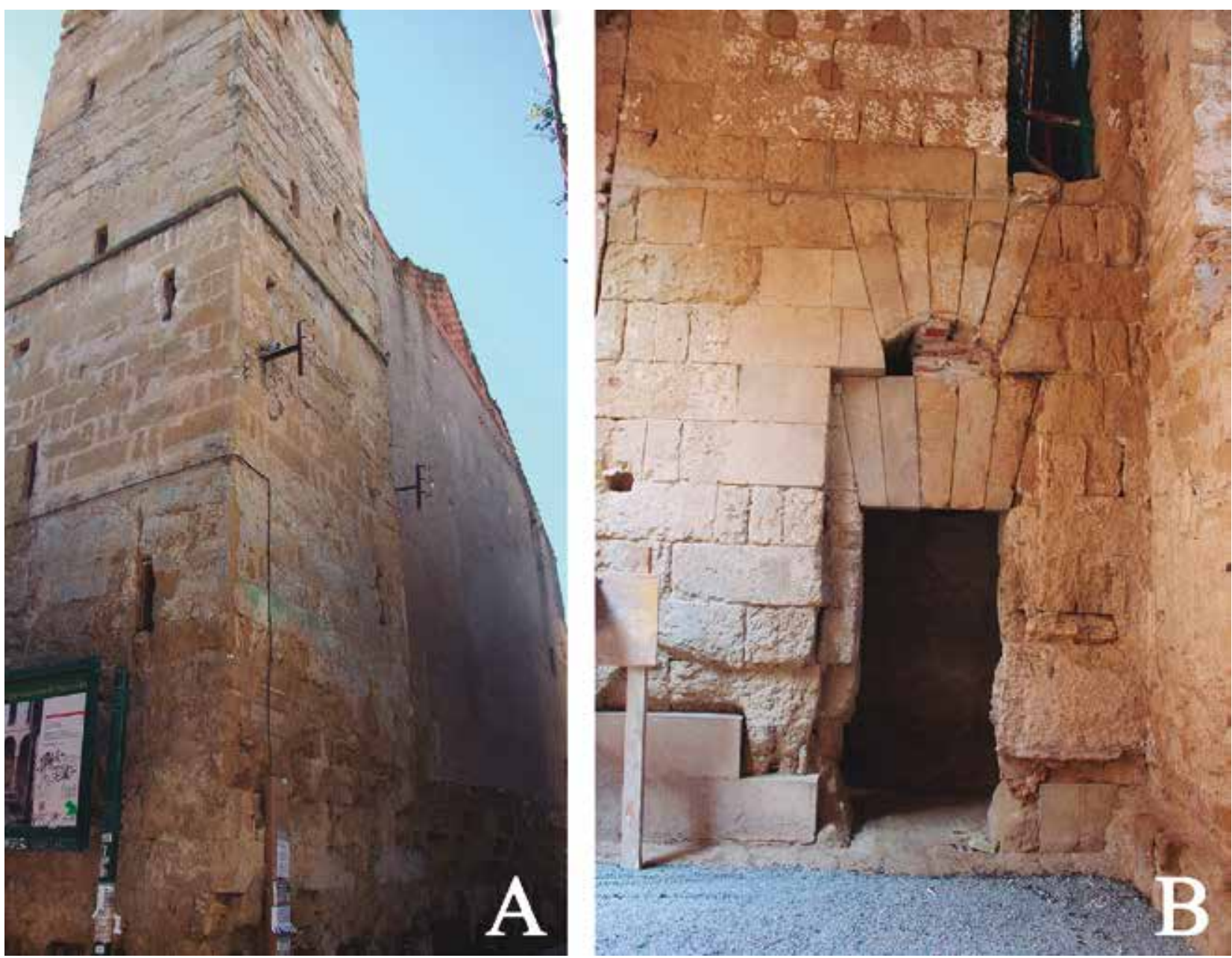

Fig. 13. Córdoba (antigua iglesia de Santa Catalina): A. Vista del alminar desde el exterior. B. Puerta de acceso al alminar (C. González). / Córdoba (former church of Santa Catalina): A. External view of the minaret. B. Access door to the minaret (C. González).

\footnotetext{
${ }^{21}$ Con el uso cristiano del edificio, el alminar se recreció hasta duplicar la altura de lo islámico conservado hasta entonces, es decir, hasta alcanzar los $18 \mathrm{~m}$. Además, se desmontó la terraza y se desmocharon parte de las fachadas y del machón central. Junto con ello, se practicaron sendas ventanas en los muros sureste y noroeste.

${ }^{22}$ Resulta curioso comprobar cómo V. Escribano también es consciente de esas diferencias, pero no las detalla ni considera que sean el resultado de dos momentos cronológicos distintos (Escribano, 1964-65, 87).
} 


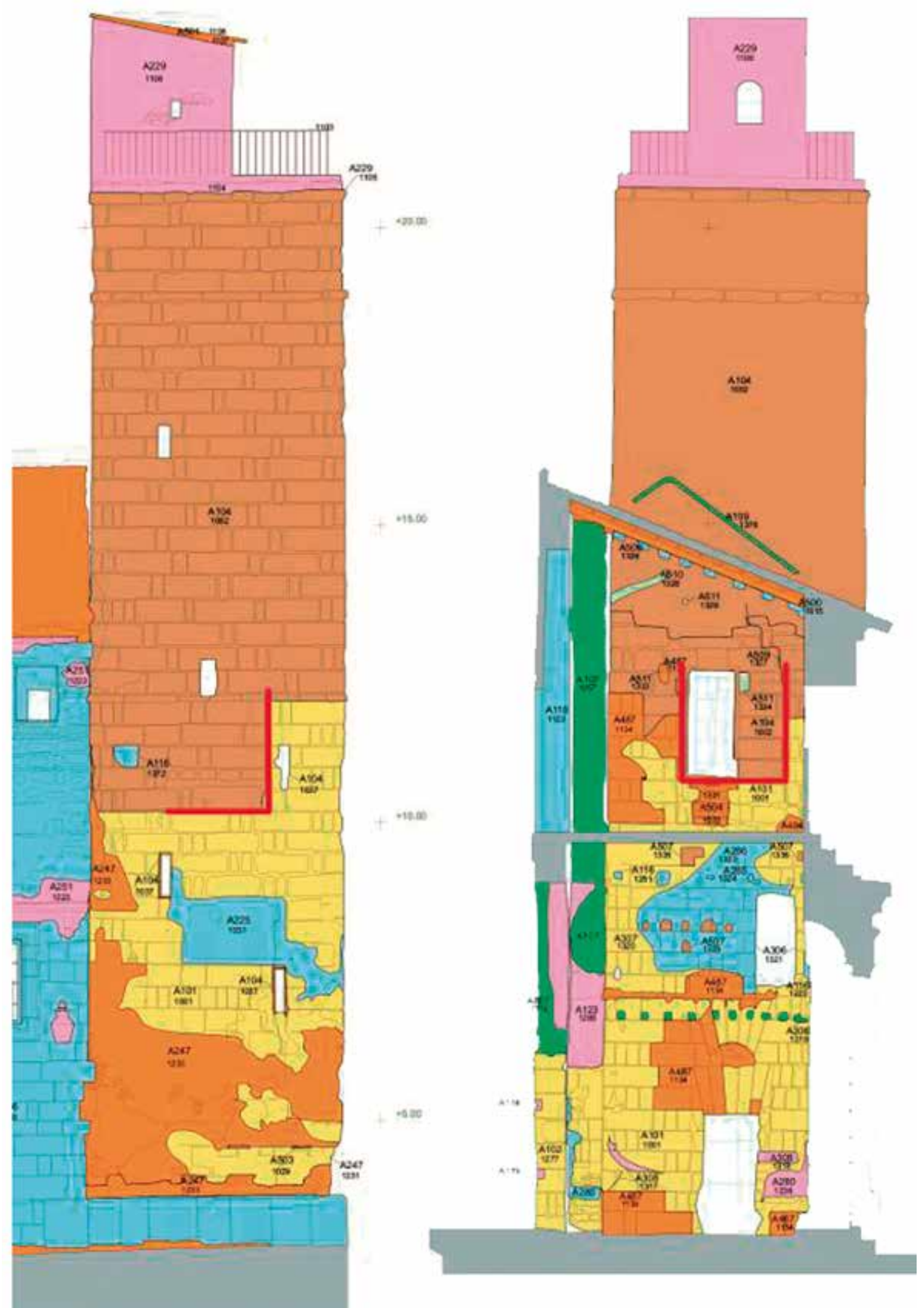

Fig. 14. Córdoba (antigua iglesia de Santa Catalina): huellas de las posibles ventanas del alminar, según Caballero et al., en sus frentes noreste y sureste respectivamente (Caballero et al., 2007: planos 02 y 07, con modificaciones). / Córdoba (former church of Santa Catalina): traces of the minaret's possible former windows, according to Caballero et al., that can be seen in the north-east and south-east faces, respectively (Caballero et al., 2007: plans 02 y 07, with modifications). 


\section{e) Cronología}

La tipología de doble cuadrado a la que corresponde esta mezquita ( vid. apdo. a) nos lleva a confirmar su cronología califal. No obstante, existen otros elementos que nos permiten precisar con algo más de exactitud en qué momento del Califato pudo haberse erigido. Ya V. Escribano sugirió una cronología de finales del califato para esta mezquita, diciendo que el edificio "se debió levantar tardíamente, a finales del siglo $X 0$ principios del siglo XI, pongamos hacia el año 1000, en época amirí, y por tanto anterior a la caída del califato en época de Almanzor" (Escribano, 1964-65: 85). Posteriormente, y basándose en la modulación de los sillares, F. Hernández apoyó esa propuesta, fijando la construcción de mezquita y alminar -a los que considera elementos coetáneos- en un momento comprendido entre la muerte de al-Hakam II y la fitna (Hernández, 1975: 208). La misma datación mantienen L. Olmo, a partir de los datos obtenidos en su excavación, y M. A. Jordano, quien, como hemos visto, considera que la puerta conservada en el testero suroeste de la mezquita tiene una filiación califal tardía (Jordano, 2002: 45-46).

Cuando se refiere a la cronología del conjunto, L. Caballero aborda una problemática distinta, relacionada con la posible existencia de distintas fases constructivas y funcionales para el mismo. Aunque data los restos existentes del edificio en época califal, Caballero no apoya la construcción coetánea de mezquita y alminar debido, fundamentalmente, a las diferencias edilicias que observa en el aparejo de ambas partes ${ }^{22}$. Mientras que el muro de fachada noroeste de la mezquita, correspondiente al sahn, presenta falso almohadillado, los sillares del alminar son lisos tanto al interior como al exterior. Otra diferencia con respecto al resto de la mezquita es que en sus esquinas se cuentan con frecuencia tres tizones, cuando en las de la masŷid solo se suele apreciar uno. Según Caballero, los muros del alminar no se entrelazan con los del resto del edificio (Caballero et al., 2007: 20). Por ello, este autor lanza la propuesta de que quizás pudo haber una mezquita anterior a la califal tardía, si bien la independencia edilicia de ambas construcciones pudo haberse debido a una estrategia para protegerlas a ambas, y no necesariamente a la existencia de dos momentos constructivos diferentes.

A este respecto, algunos autores defienden la contemporaneidad de la mezquita y el alminar, dada "la identidad de su fábrica con la de los muros y los contrafuertes del lado SO" (Calvo, 2014: 582). Pero, según L. Caballero, la cimentación del alminar, hecha con sogas, solo se detecta en su lado sureste. Opina que "el alminar es independiente del cuerpo de la mezquita que hoy conocemos, y por lo tanto suponemos que se construyó bien en un momento anterior, si los restos incluidos en la IA pertenecian a una mezquita previa totalmente arrasada hasta apenas dejarnos visibles escasos restos de uno de sus muros, algo que no podemos confirmar en el momento actual; o bien en un momento coetáneo, aunque por un taller distinto o simplemente con una técnica diferente" (Caballero et al., 2007: 20). No obstante, F. Hernández afirma que mezquita y alminar sí compartían cimientos, pero no muros en alzado (vid. supra). Junto con ello, P. Marfil no ha hallado indicios de la existencia de una mezquita anterior, o de una fase previa de la misma. Por último, de los comentarios que tanto A. Ramírez Laguna como F. De la Fuente hicieron de las excavaciones de F. Hernández puede deducirse que los cimientos de la mezquita y del alminar sí encajaban entre ellos. Esta problemática, junto con la ya reseñada de las ventanas, no es sino una muestra más de los despropósitos arqueológicos a los que, en ocasiones, este edificio se ha visto expuesto.

\subsection{Fase tardoislámica (SS. XI-XIII)}

Ninguno de los autores consultados hasta el momento hace referencia a los posibles usos o evolución de este inmueble en la etapa inmediatamente posterior a la caída del califato omeya. Tan solo L. Caballero menciona que "la mezquita islámica sufrió en este momento intermedio la ruina" (Caballero et al., 2007: 59), refiriéndose a que, a mediados del siglo XIII, el edificio experimentó varias labores de saneado previas a su conversión en iglesia, sin que pueda especificarse su estado entre los siglos XI y estas tareas de transformación. Los trabajos de este autor consignan reformas e incluso refacciones en algunos puntos muy concretos de la antigua mezquita (en las arquerías de la sala de oración, en su cubierta y en su fachada hacia el patio), que respaldan su estado ruinoso y la consiguiente necesidad de reformarla para adecuarla a los nuevos usos. No obstante, "el desconocimiento acerca de la vida de esta mezquita y su uso desde su construcción hasta la toma de la ciudad, dificulta determinar, de forma más concreta, este periodo" (Caballero et al., 2007: 59) así como concretar si en algún momento dejó de utilizarse, y por qué motivos.

\section{CONCLUSIONES}

A la espera de la puesta en marcha de una necesaria labor de consolidación y restauración de la antigua iglesia de Santa Catalina, la sistematización de la documentación publicada (en ocasiones inédita) y la revisión puntual in situ de las estructuras conservadas, ha permitido que conozcamos con mayor precisión la historia de este céntrico solar cordobés a lo largo de casi mil años.

\footnotetext{
${ }^{22}$ Resulta curioso comprobar cómo V. Escribano también es consciente de esas diferencias, pero no las detalla ni considera que sean el resultado de dos momentos cronológicos distintos (Escribano, 1964-65, 87).
} 
En relación con la etapa bajoimperial, el registro arqueológico apunta hacia una ocupación de baja densidad, materializada en un pozo negro y en un enterramiento. Ambos podrían ponerse en relación con algún establecimiento residencial y/o productivo, hoy por hoy desconocido, situado en las inmediaciones. Esta imagen, que cobra sentido si tenemos en cuenta la evolución de otros solares cercanos, se alteró con motivo de la construcción de un peculiar ambiente. Se trata de un espacio ornamentado con un mosaico geométrico, de datación desconocida y que formaría parte de un edificio mayor, que fue sustituido hacia el siglo VI por un inmueble cuya planta no parece corresponderse con las distintas planimetrías sugeridas hasta la fecha (al haberse identificado ciertas incoherencias), y de adscripción un tanto problemática.

Aun cuando el único argumento que, desde nuestro punto de vista, permite plantear su interpretación como un edificio de carácter religioso es la simbología cristiana de uno de los mosaicos que lo decoraban (cuyos motivos también aparecen en construcciones profanas), la posibilidad de que nos encontremos ante una domus tampoco está exenta de problemas ya que de ser así se trataría de un unicum en el panorama hispano. Solo futuras intervenciones permitirán precisar la exacta planta y cronología de una construcción caracterizada por su indudable vinculación a las élites y por su cercanía al complejo episcopal.

Con respecto a la fase islámica, el edificio que ocupó este solar fue, sin ningún género de dudas, una masŷid que guarda, además, semejanzas muy acusadas con otras mezquitas cordobesas erigidas en época califal, como por ejemplo con la mezquita de Fontanar (Zamorano y Luna, 1995; Luna y Zamorano, 1999; Calvo, 2014: 582; González Gutiérrez, 2016a: 291-292 y 330 ss.). También parece haber un consenso general en cuanto a su datación en época califal tardía, pero ello plantea un pequeño dilema que creemos interesante reseñar, y que se relaciona con los usos que recibió el solar desde su abandono hasta su adecuación para la construcción de la mezquita, varios siglos después. Dado que nos encontramos en pleno corazón de la medina islámica, en un lugar muy próximo a la mezquita aljama y, por tanto, en una zona presumiblemente activa y concurrida, llama la atención que una parcela de estas características, aún ocupada por un inmueble tardoantiguo (o sus restos), permaneciese intacta hasta finales del siglo X. En alguna ocasión se ha especificado que hubo un hiato ocupacional entre la época tardoantigua y la posterior construcción de la mezquita ${ }^{23}$, lo cual añade controversia a la cuestión. Pero, fuera como fuese, no parece que los muros del edificio previo condicionasen de manera importante la erección de la posterior mezquita (Caballero et al., 2007: 13).
Es interesante, asimismo, la información que se extrae de su ubicación, de la que no se ocupa ninguno de los estudios precedentes: Este edificio religioso se proyectó en una vía de comunicación de la ciudad califal que, como llevamos visto, era importante ya desde momentos preislámicos. Durante la ocupación musulmana, esta vía desembocaba en la puerta sureste de la ciudad, la Bāb al-Hadīd, luego llamada de la Pescadería o de los Calceteros. Al mismo tiempo, se construyó muy cerca de la mezquita aljama. Estas características parecen indicar que la erección de esta pequeña mezquita no pretendió, al menos únicamente, cubrir las necesidades religiosas de los habitantes del barrio, puesto que, para ello, la presencia de la mezquita mayor ya habría sido suficiente. Su ubicación en una arteria de comunicación parece hablarnos, más bien, de su papel como elemento islamizador y creador de una imagen urbana muy específica y típicamente musulmana. Estas pautas de inserción urbanística se han detectado en otras masâŷid cordobesas (vid. González Gutiérrez, 2016a: cap. 8.2), y podrían estar vinculadas también con acciones promovidas directamente por los gobernantes, por miembros de la familia reinante 0 círculos sociales afines, con el objetivo de estimular la propaganda y la adhesión a los omeyas.

Pese a los interrogantes que todavía persisten, a través de la presente contribución esperamos haber ayudado a ordenar y sistematizar la dispar e inconexa documentación sobre este céntrico inmueble cordobés, poniendo de relieve determinados puntos y aspectos problemáticos, en los que apenas se han detenido los distintos investigadores que nos han precedido y sobre los que hemos pretendido arrojar algo de luz al respecto. Del mismo modo, mediante nuestro trabajo confiamos haber contribuido al futuro planeamiento de las intervenciones arqueológicas y las labores de restauración que puedan desarrollarse en su seno. Esperamos también que, dado el bagaje histórico y arqueológico que esta construcción alberga, las autoridades locales apuesten decididamente por la rehabilitación y apertura de este edificio histórico, por su investigación sistemática, y por su incorporación al equipamiento cultural de la ciudad.

\section{AGRADECIMIENTOS}

La elaboración del presente artículo hubiese sido imposible sin la ayuda de un variado elenco de profesionales a quienes agradecemos sus distintas aportaciones y comentarios: Dr. Alberto León Muñoz (Universidad de Córdoba), Dr. P.F. Marfil Ruiz (Universidad de Córdoba), Dr. Juan Francisco Murillo Redondo (Gerencia Municipal de Urbanismo del Ayuntamiento de Córdoba), Dr. A. López García, Dra. Mª.A. Utrero Agudo (Consejo

\footnotetext{
${ }^{23}$ Como en la conferencia titulada "La iglesia tardoantigua de Santa Clara en Córdoba", a cargo de P. Marfil, celebrada en la Facultad de Filosofía y Letras el 21 de septiembre de 2012.
} 
Superior de Investigaciones Científicas y Escuela de Estudios Árabes), E. Cerrato Casado (Università di Padova), J.Mª Tamajón Navarro y U. Tejedor García.

\section{BIBLIOGRAFIA}

Azkarate, A., 2002. De la tardoantigüedad al medievo cristiano. Una mirada a los estudios arqueológicos sobre el mundo funerario. En: Vaquerizo, D. (ed.), Espacios y usos funerarios en el Occidente romano, 115-140. Universidad de Córdoba. Córdoba.

Baldassarri, P., 2011. Archaeological Excavations at Palazzo Valentini. A Residential Area in the Shade of the Trajan's Forum. En: Sahin, M. (ed.), 11th International Colloquium on Ancient Mosaics. Mosaics of Turkey and Parallel Developments in the Rest of the Ancient and Medieval World: Questions of Iconography, Style and Technique from the Beginnings of Mosaic until the Late Byzantine Era, 43-47. Yayinlari. Estambul.

Baldini, I., 2001. La domus tardoantica: forme e rappresentazioni dello spazio domestico nelle città del Mediterraneo. University Press Bologna, Bolonia.

Brogiolo, G.P., 2011. Le origini della città medievale. Societá Archeologica, Mantua.

Caballero, L., Murillo, I., Utrero, M.A., Peláez, F., Arce, F., Monteira, I., Moreno, F., Martín, R., Lucena., J.M., Westman, A., 2007. Estudio de Arqueología de la Arquitectura del convento de Santa Clara de Córdoba. Fundación Caja Madrid, Madrid.

Calvo, S., 2014. Las mezquitas de al-Andalus. Fundación Ibn Tufayl de Estudios Árabes. Almería.

Carrillo, J.R., Hidalgo, R., Murillo, J.F., Ventura, A., 1999. Córdoba de los orígenes a la Antigüedad Tardía. En: García, F.R. y Acosta, F. (coords.), Córdoba en la historia: la construcción de la urbe, 37-74. Ayuntamiento de Córdoba, Córdoba.

De Matteis, L.M., 2004. Mosaici di Cos. Dagli scavi delle missioni italiane e tedesche (1900-1945). Scuola Archeologica Italiana di Atene, Atenas.

Dobado, J., Yllescas, Mª, 2014. Córdoba: ciudad conventual. Ayuntamiento de Córdoba, Córdoba.

Escribano, V., 1964-1965. La mezquita de la calle Rey Heredia. Al-Mulk 4, 83-101.

García, E., 2012. La Sevilla tardoantigua diez años después (2000-2010). En: Beltrán, J. y Rodríguez, O. (eds.), Hispaniae urbes: Investigaciones arqueológicas en ciudades históricas, 881-925. Universidad de Sevilla, Sevilla.

González Gutiérrez, C., 2012. Las mezquitas de barrio de Madinat Qurtuba: una aproximación arqueológica. Diputación de Córdoba, Córdoba.

González Gutiérrez, C., 2016a. Las mezquitas de la Córdoba islámica. Concepto, tipología y función urbana. Tesis Doctoral (inédita). Universidad de Córdoba, Córdoba.

González Gutiérrez, C., 2016b. Las mezquitas de barrio de Madinat Qurtuba 15 años después: espacios religiosos urbanos en la capital andalusí. Anales de Arqueología Cordobesa 27, 267-292.

González Gutiérrez, C., 2017. Metrología y modulación en las mezquitas: propuesta de análisis a través de cuatro casos cordobeses. Arqueología de la Arquitectura 14, 1-14.

Hernández, F., 1975. El alminar de Abd al-Rahman III en la Mezquita Mayor de Córdoba: génesis y repercusiones. Patronato de la Alhambra, Granada.
Jordano, $M^{a}$ A., 2002. Arquitectura medieval cristiana en Córdoba. Tesis Doctoral. Universidad Complutense de Madrid, Madrid.

Jordano, $M^{a}$ A., 2013. Escudos de Córdoba y provincia en fachadas y portadas. Universidad de Córdoba, Córdoba.

Luna, D., Zamorano, A., 1999. La mezquita de la antigua finca El Fontanar (Córdoba). Cuadernos de Madinat al-Zahra 4 145-173.

Marfil, P.F., 1996a. Informe y memoria científica de la I.A.U. Iglesia del convento de Santa Clara, c/ Rey Heredia, Córdoba. Informe administrativo (inédito) depositado en la Delegación Provincial de Cultura de la Junta de Andalucía. Junta de Andalucía, Córdoba.

Marfil, P.F., 1996b. La iglesia paleocristiana de Santa Catalina en el Convento de Santa Clara (Córdoba). Caetaria 1, 33-45.

Marfil, P.F., 1996c El templo paleocristiano descubierto en la antigua iglesia del convento de Santa Clara, de Córdoba. Boletín de la Real Academia de Córdoba 67, 197-210.

Marfil, P.F., 2000. La sede episcopal cordobesa en época bizantina: evidencia arqueológica En: Gurt, J.Ma .,y Tena, N. (eds.), V Reunió d'Arqueologia Cristiana Hispànica, 157-176. Institut d'Estudis Catalans, Barcelona.

Montejo, A., 1998. Informe Sucinto de los resultados obtenidos durante la Intervención Arqueológica de Urgencia en Magistral González Francés $n^{\circ}$ 23. Córdoba. Informe administrativo (inédito) depositado en la Delegación Provincial de Cultura de la Junta de Andalucía. Junta de Andalucía, Córdoba.

Monterroso, A. J., 2002. La secuencia estratigráfica: Evolución histórica del teatro de Colonia Patricia. En: Ventura, A. et al. (ed.), El teatro romano de Córdoba. Catálogo de la exposición, 133-146. Universidad de Córdoba, Córdoba.

Monterroso, A.J., Cepillo, J.J., 2002. La ocupación medieval. Evolución histórica del teatro de Colonia Patricia. En: Ventura, A. et al. (ed.), El teatro romano de Córdoba. Catálogo de la exposición, 161-172. Universidad de Córdoba, Córdoba.

Olmo, L., 1981. Informe preliminar de las excavaciones realizadas en el antiguo Convento de Santa Clara en Córdoba. Informe administrativo (inédito). Córdoba.

Orfila, M., 2009. La vajilla Terra Sigillata Hispánica Tardía Meridional. En: Bernal, D., Ribera, A.V. (eds.), Cerámicas hispanorromanas. Un estado de la cuestión, 541-551. Universidad de Cádiz, Cádiz.

Penco, F., 2000. Un pavimento musivo de influencia bizantina en el antiguo convento de Santa Clara de Córdoba. En: Gurt, J.M ${ }^{\mathrm{a}}$, Tena, N. (eds.), V Reunió d'Arqueologia Cristiana Hispànica, 245-262. Institut d'Estudis Catalans, Barcelona.

Penco, F., 2002. Apuntes sobre un excepcional mosaico de influencia bizantina en el antiguo convento de Santa Clara de Córdoba. Meridies 5-6, 7-28.

Perich, A., 2014. Arquitectura residencial urbana d'època tardoantiga a Hispania (segles IV-VIII d.C.). Tesis doctoral (inédita). Universitat Rovira i Virgili, Tarragona.

Rascón, S., Sánchez, A.L., 2015. Complutum: modelo urbanístico para una ciudad romana privilegiada en los siglos III-V. En: Brassous L., Quevedo. A. (eds.), Urbanisme civique en temps de crise. Les espaces publics d'Hispanie et de l'Occident romain entre les Ile et IVe s, 199-220. Casa de Velázquez, Madrid.

Rodriguez, J.F., 1987. Perfil histórico de Córdoba en la época visigoda (I). Boletín de la Real Academia de Córdoba 113, 141-153. 
Ruiz Bueno, M.D., 2015. El kardo maximus de Córdoba en la Antigüedad Tardía. Anales de Arqueología Cordobesa 25-26, 83-113.

Ruiz Bueno, M.D., 2016. Topografía, imagen y evolución urbanística de la Córdoba clásica a la tardoantigua (ss. II-VII d.C.). Tesis Doctoral (inédita). Universidad de Córdoba, Córdoba.

Ruiz Bueno, M.D., 2017. Enterramientos hispanos tardoantiguos in urbe: algunas reflexiones y tendencias. En: Diarte, P. (ed.), Cities, Lands and Ports in Late Antiquity and the Early Middle Ages: Archaeologies of Change, 23-38. BraDypUS, Roma.

Sánchez Ramos, I.M., 2006. La cristianización de la topografía funeraria en las provincias occidental del Imperio: exemplum cordubense. Tesis Doctoral. Universidad de Córdoba, Córdoba.

Sánchez Ramos, I.M., 2007. La cristianización de las necrópolis de Corduba. Fuentes escritas y testimonios arqueológicos. Archivo Español de Arqueología 80, 191-206.

Sánchez Ramos, I.M., 2009. Sobre el grupo episcopal de Corduba. Pyrenae 40(1), 121-147.

Sánchez Ramos, I.M., 2010. Corduba durante la Antigüedad tardía. Las necrópolis urbanas. Archaeopress, Oxford.

Sánchez Velasco, J., 2006. Elementos arquitectónicos de época visigoda en el Museo Arqueológico de Córdoba. Junta de Andalucía, Sevilla.

Saradi, H., 1998. Privatisation and subdivision of urban properties in the early Byzantine centuries: social and cultural implications. Bulletin of the American Society of Papyrologists 35, 17-43.

Santangeli, R., 2011. Edilizia residenziale in Italia nell' altomedioevo. Carocci editore, Roma.
Utrero, M.A., 2008. Late Antique churches in the south-eastern Iberian Peninsula: The Problem of Byzantine Influence. Millennium 5, 191-212.

Utrero, M.A., 2009. Las iglesias cruciformes del siglo VII en la Península Ibérica. Novedades y problemas cronológicos y morfológicos de un tipo arquitectónico. En: Caballero, L., Mateos, P. y Utrero M ${ }^{a}$. A. (eds.), El siglo VII frente al siglo VII. Arquitectura, 133-154. Consejo Superior de Investigaciones Científicas, Madrid.

Vaquerizo, D., Ruiz, M.D., 2014. Últimas investigaciones arqueológicas en Corduba, Colonia Patricia: una propuesta de síntesis. En: Martín Bueno, M. y Sáenz, J.C. (eds.), Modelos edilicios y prototipos en la monumentalización de las ciudades de Hispania, 15-31. Universidad de Zaragoza, Zaragoza.

Ventura, A., Márquez, C., Monterroso, A., Carmona, M.A., 2002. El teatro romano de Córdoba. Catálogo de la exposición. Universidad de Córdoba, Córdoba.

Ventura, A., Pizarro, G., 2010. El Aqua Augusta (acueducto de Valdepuentes) y el abastecimiento de agua a Colonia Patricia Corduba: investigaciones recientes (2000-2010). En: AA.VV. Las técnicas y las construcciones en la ingeniería romana. $V$ congreso de las obras públicas romanas, 177-203. Fundación de la Ingeniería Técnica de Obras Públicas, Madrid.

Vizcaíno, J., 2009. La presencia bizantina en Hispania (siglos VI-VII). La documentación arqueológica. Universidad de Murcia, Murcia.

Zamorano, A., Luna, D., 1995. Excavación Arqueológica de Urgencia en el Sistema General U-1 (Finca Fontanar, Córdoba). Anuario Arqueológico de Andalucía 1992 (vol. III), 161-172. 